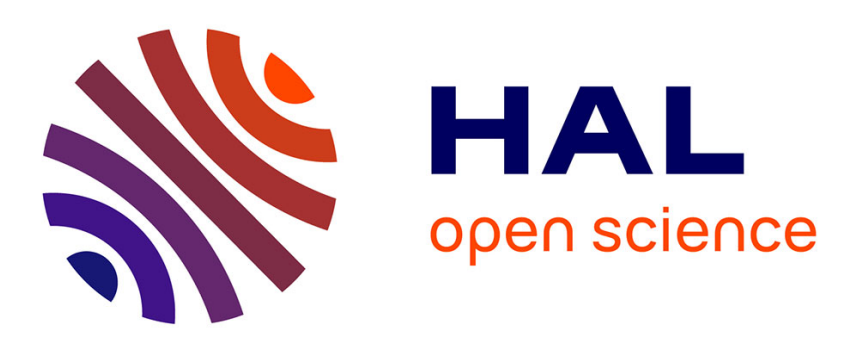

\title{
Dialkyl 1-Alkynylphosphonates: A Range of Promising Reagents
}

Bogdan Iorga, Frédéric Eymery, Duncan Carmichael, Philippe Savignac

\section{To cite this version:}

Bogdan Iorga, Frédéric Eymery, Duncan Carmichael, Philippe Savignac. Dialkyl 1Alkynylphosphonates: A Range of Promising Reagents. European Journal of Organic Chemistry, 2000, 18, pp.3103-3115. 10.1002/1099-0690(200009)2000:183.0.co;2-v . hal-03161491

\section{HAL Id: hal-03161491 \\ https://hal.science/hal-03161491}

Submitted on 11 Mar 2021

HAL is a multi-disciplinary open access archive for the deposit and dissemination of scientific research documents, whether they are published or not. The documents may come from teaching and research institutions in France or abroad, or from public or private research centers.
L'archive ouverte pluridisciplinaire HAL, est destinée au dépôt et à la diffusion de documents scientifiques de niveau recherche, publiés ou non, émanant des établissements d'enseignement et de recherche français ou étrangers, des laboratoires publics ou privés. 


\title{
Dialkyl 1-Alkynylphosphonates, a Range of Promising Reagents
}

\author{
Bogdan Iorga, ${ }^{[a]}$ Frédéric Eymery, ${ }^{[a]}$ Duncan Carmichael, ${ }^{[a]}$ and Philippe \\ Savignac $^{[a]}$
}

${ }^{[a]}$ Laboratoire Hétéroéléments et Coordination, UMR CNRS 7653, DCPH - Ecole Polytechnique, 91128 Palaiseau Cedex, France

Fax: +3316933 3990

E-mail:dcph@poly.polytechnique.fr

1-alkynylphosphonates / halogen abstraction / SNP(V) / $\beta$-elimination / cycloaddition reactions / reduction / hydration

The present review covers the preparations of 1-alkynylphosphonates by Michaelis-Arbuzov and Michaelis-Becker reactions, nucleophilic substitutions at phosphorus (SNP(V)) and elimination from 1-alkenylphosphonates. Their reactivity and versatility have made them valuable precursors for other phosphonates and particularly for the synthesis of heterocycles by [2+2], [3+2] and [4+2] cycloaddition reactions.

\section{Introduction}

Diethyl 1-propynylphosphonate, the first 1-alkynylphosphonate, was described in $1957^{[1]}$ and the syntheses forming the basis of modern alkynylphosphonate chemistry were elaborated in the 1960's. The methodologies developed during this period for the synthesis of 1alkynylphosphonates used synthetic concepts which were new to phosphorus chemistry, such as "charge affinity inversion" and "positive halogen abstraction". Four main reaction categories allow the preparation of 1-alkynylphosphonates: the "apparent" Michaelis-Arbuzov and Michaelis-Becker reactions, the phosphite-allenylphosphonate rearrangement, carbanionic displacements at quinquevalent phosphorus centers $(\mathrm{SNP}(\mathrm{V}))^{[2]}$ and conversions of vinyl- to alkynylphosphonates by addition-elimination reactions. The first three synthetic procedures rely on the preparation of a terminal alkyne, bearing either a proton or a halide, prior to construction of the C-P bond. The fourth procedure offers a complementary and more versatile multi-step approach involving the elaboration of suitably substituted vinylphosphonates prior to unmasking the triple bond. In this review, particular emphasis will be placed upon synthetic methods and chemistry which are peculiar to 1-alkynylphosphonates.

\section{General Methods of Synthesis}

\section{A. Nucleophilic Displacement Reactions by Phosphorus Nucleophiles}

\section{Michaelis-Arbuzov Reaction}

In 1962 it was reported that $\alpha$-bromoalkynes $2(\mathrm{X}=\mathrm{Br})$ whose triple bond is conjugated to a benzene ring or other multiple bond react surprisingly easily with trialkyl phosphites 1. A 
subsequent Michaelis-Arbuzov-type rearrangement gives dialkyl 1-alkynylphosphonates 3 in fair to good yields (48-67\%) (Scheme 1). ${ }^{[3]}$

$$
\begin{array}{ccc}
(\mathrm{RO})_{3} \mathrm{P} & +\mathrm{X}-\mathrm{C} \equiv \mathrm{C}-\mathrm{R}^{1} \\
\mathbf{1} & \mathrm{X}=\mathrm{Cl}, \mathrm{Br} \quad \mathbf{2} & (\mathrm{RO})_{2} \mathrm{P}-\mathrm{C} \equiv \mathrm{C}-\mathrm{R}^{1}+\mathrm{R}-\mathrm{X} \\
\mathrm{O} & \mathbf{3}
\end{array}
$$

\section{Scheme 1}

Chloro-, bromo- and iodoalkylacetylenes which are not conjugated to an unsaturated system do not react. However, the presence of electronegative atoms or groups increases the reactivity of the haloacetylene functionality, so that substituted haloacetylenes $2(\mathrm{X}=\mathrm{Cl}$ or $\mathrm{Br})$ undergo an "apparent" Michaelis-Arbuzov reaction with trialkyl phosphites $\mathbf{1}$ when $\mathrm{R}^{1}$ is an electronwithdrawing or accommodating group $\left(\mathrm{R}^{1}=\mathrm{Ph}^{[4]}{ }^{[4} \mathrm{C}_{6} \mathrm{~F}_{5},{ }^{[5]} \mathrm{R}-\mathrm{C} \equiv \mathrm{C},{ }^{[6]} \mathrm{CH}_{2}=\mathrm{CH},{ }^{[7]} \mathrm{Cl},{ }^{[4,8,9]} \mathrm{Br},{ }^{[9,10]}\right.$ $\left.(\mathrm{EtO}){ }_{2} \mathrm{P}(\mathrm{O}),{ }^{[8,11,12]} \mathrm{SR}^{[13,14]} \mathrm{SiMe}_{3},{ }^{[15,16]} \mathrm{SnEt}_{3}{ }^{[17,18]}\right)$.

The Michaelis-Arbuzov rearrangement of dichloroacetylene 5 proceeds under surprisingly mild conditions even in the cold in ethereal solution, to give mainly the monosubstitution product. For example, the reaction of triethyl phosphite 4 (1 eq.) with a large excess of dichloroacetylene 5 (5 eq.) furnishes diethyl 2-chloroethynylphosphonate 6 in $50 \%$ yield (Scheme 2). A better yield $(90 \%)$ has been reported by working at $-20^{\circ} \mathrm{C}^{[19]}$ However, the chlorine atom in the product phosphonate 6, which is rather labile because of the polarization induced by the highly electronwithdrawing phosphoryl group, can undergo a further Michaelis-Arbuzov rearrangement with formation of tetraethyl acetylenediphosphonate 7 in $52 \%$ yield. $^{[4]}$
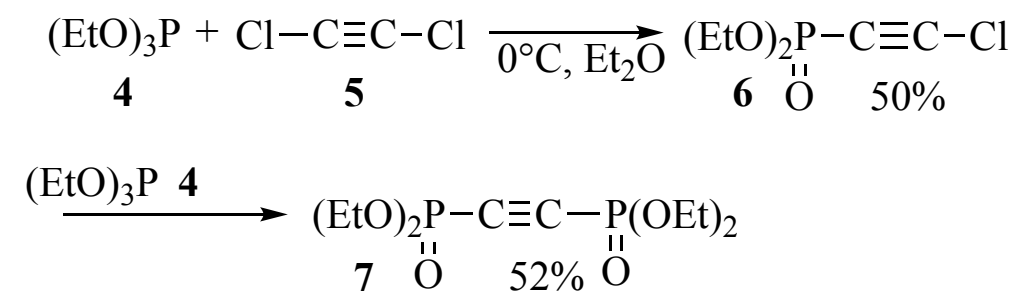

\section{Scheme 2}

Dialkyl ethynylphosphonates are the simplest but not the easiest of these compounds to prepare. Whilst several approaches were described, no convenient high-yield synthesis appeared until the introduction of the trimethylsilyl functionality as a protecting group for the acetylenic $\mathrm{CH}$ linkage. The synthesis of diethyl ethynylphosphonate $\mathbf{1 0}$ then involves an "apparent" MichaelisArbuzov reaction between chloroethynyltrimethylsilane $\mathbf{8}$ and triethyl phosphite $\mathbf{4}$ under heating at reflux for $5 \mathrm{~h}$. The trimethylsilyl group is sufficiently electron accommodating to promote the reaction. The resulting diethyl trimethylsilylethynylphosphonate 9, obtained in high yields (70$82 \%$ ), may be readily desilylated by $10 \%$ aqueous sodium carbonate to give the required diethyl ethynylphosphonate $\mathbf{1 0}$ in overall yields up to $77 \%$ (Scheme 3$){ }^{[15]}$
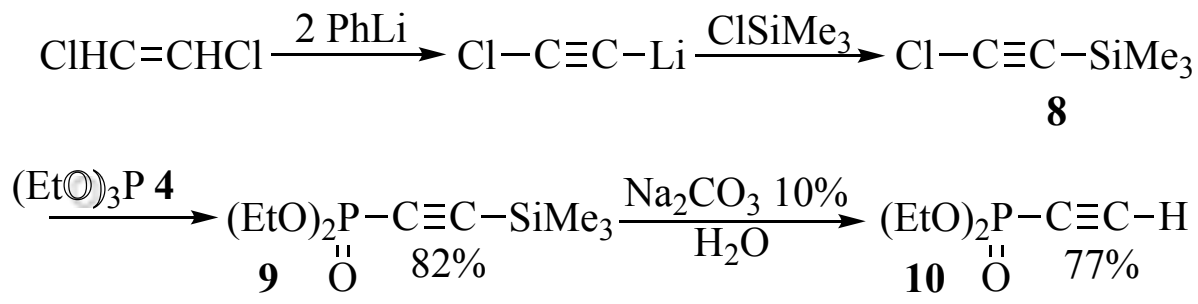

\section{Scheme 3}


In view of the supposed inertness of halo-unsaturated substrates in the Michaelis-Arbuzov reaction, it is remarkable that arylalkynyl halides are more reactive than comparable alkyl, aryl, or vinyl halides towards trialkyl phosphites 1. The success of the Michaelis-Arbuzov reaction in the synthesis of dialkyl 1-alkynylphosphonates $\mathbf{3}$ from haloalkynes $\mathbf{2}$ has provoked a number of mechanistic studies. Three sites, the halogen, $\alpha$-carbon, or $\beta$-carbon have been investigated as the zone of the initial nucleophilic attack by trialkyl phosphites $\mathbf{1}$. Studies to date suggest that the reaction proceeds by at least two different mechanisms, and that probably the most important of these involves positive halogen-abstraction (path a) as outlined in Scheme 4. ${ }^{[20-24]}$

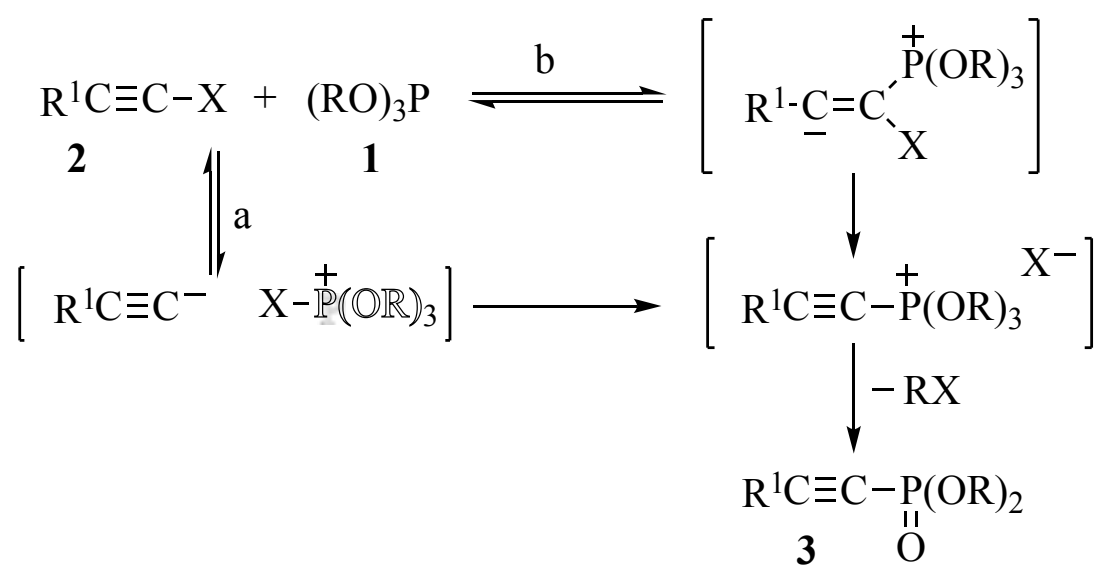

\section{Scheme 4}

The second mechanism operating may well be the addition / elimination mechanism (path b), also outlined in Scheme 4. The negative charge developing at the $\beta$-carbon in the intermediate is consistent with the requirement for electron-withdrawing or accommodating $\mathrm{R}^{1}$ groups. The first mechanism also satisfies this requirement.

The treatment of propargyl bromide with trialkyl phosphites $\mathbf{1}$ has been reported to give complex reaction mixtures. For example, from the reaction between triethyl phosphite 4 and propargyl bromide at $90^{\circ} \mathrm{C}$ only the diethyl 1-propynylphosphonate $18(\mathrm{R}=\mathrm{Et})$ was isolated in low yields $(15 \%){ }^{[25,26]}$

Early transformation of trialkyl phosphites 1 and haloalkynes $2\left(\mathrm{R}^{1} \mathrm{C} \equiv \mathrm{CX}\right)$ into dialkyl 1alkynylphosphonates 3 was limited to haloalkynes in which $\mathrm{R}^{1}$ was an electron-withdrawing group. ${ }^{[2,27]}$ In 1990, two innovations worthy of merit were reported. ${ }^{[28,29]}$ The first featured alkynylphenyliodonium salts ${ }^{[28]}$ as alkynylating agents and the second featured $\mathrm{NiCl}_{2}$ as a catalyst. ${ }^{[29]}$ Alkynylphenyliodonium tosylates $\mathbf{1 1}$ react with trialkyl phosphites $\mathbf{1}$ in a formal Michaelis-Arbuzov reaction to give dialkyl 1-alkynylphosphonates 3 (Scheme 5). It seems plausible that the first step in this reaction is a Michael addition of the trimethyl phosphite $\mathbf{1}(\mathrm{R}=\mathrm{Me})$ to the electron-deficient $\beta$-carbon to form an ylide which undergoes loss of iodobenzene and formation of vinylidene. The rearrangement of this carbene affords the alkyne phosphonium which is transformed into 3 and ROTs according to the second step of the Michaelis-Arbuzov reaction. ${ }^{[30]}$ For example, when an excess of neat trimethyl phosphite $1(\mathrm{R}=\mathrm{Me})$ was added to solid (tertbutylethynyl)phenyliodonium tosylate $11\left(\mathrm{R}^{1}=t\right.$-Bu) at room temperature, the iodonium salt rapidly disappeared to give $90 \%$ yields of dimethyl tert-butylethynylphosphonate $3\left(\mathrm{R}=\mathrm{Me}, \mathrm{R}^{1}=t\right.$ $\mathrm{Bu})$ upon work-up.

$$
\begin{aligned}
& \mathrm{TsO}^{-} \\
& \mathrm{R}^{1} \mathrm{C} \equiv \mathrm{C}-\stackrel{+}{\mathrm{IPh}}+(\mathrm{RO})_{3} \mathrm{P} \underset{-\mathrm{ROTs}-\mathrm{PhI}}{\stackrel{\text { neat } \text { r.t. }}{-}} \mathrm{R}^{1}-\mathrm{C} \equiv \mathrm{C}-\mathrm{P}(\mathrm{OR})_{2} \\
& 11 \quad 1134-90 \% \stackrel{\text { II }}{\mathrm{O}} 3
\end{aligned}
$$




\section{Scheme 5}

The reactions of $11\left(\mathrm{R}^{1}=s\right.$ - $\mathrm{Bu}, i$-Pr, $c$-Pent, $\mathrm{Ph}$ and $p$-Tol) with trimethyl and higher phosphites have been investigated. Dimethyl 1-alkynylphosphonates $3(\mathrm{R}=\mathrm{Me})$ may be isolated in yields ranging from 34 to $90 \%$. It is clear that the trimethyl phosphite-induced cleavage of the alkynylphenyliodonium ion is remarkably selective in favour of the alkynyl group. It seems plausible that the alkynylphosphonate formation is initiated by Michael addition of the trimethyl phosphite to the triple bond of $\mathbf{1 1}$ followed by vinylidene formation, rearrangement, and MichaelisArbuzov collapse. This preparation of dialkyl 1-alkynylphosphonates $\mathbf{3}$ from alkynylphenyliodonium tosylates $\mathbf{1 1}$ is a useful complement to the traditional Michaelis-Arbuzov synthesis. ${ }^{[28]}$ Simultaneously, it was reported that 1-tert-butyl-2-chloroacetylene reacts with trialkyl phosphites 1 between 110 and $160^{\circ} \mathrm{C}$ in the presence of a catalytic amount of anhydrous $\mathrm{NiCl}_{2}$ to give the corresponding alkynyl esters in good yields: $73 \%$ for the ethyl ester and $75 \%$ for the isopropyl ester. ${ }^{[2]}$

\section{Michaelis-Becker Reaction}

The first attempt to prepare 1-alkynylphosphonates 3 by a Michaelis-Becker reaction was reported in 1965 . $^{[31]}$ However, only octyne was produced when 1-bromooctyne was allowed to react with sodium diethyl phosphite 12 in liquid ammonia, the coproduct being diethyl phosphoramidate. It seems likely that reduction of the bromo compound occurs by an halogen-metal exchange, with the resulting diethyl bromophosphate being immediately converted into diethyl phosphoramidate by the liquid ammonia. ${ }^{[31]}$ The difficulties associated with this approach, namely the conversion of the bromoalkynes into sodium acetylides and the subsequent reaction of the latter with the bromophosphate byproducts, may be effectively eliminated by working at low temperature. Thus, sodium diethylphosphite 12 reacts with 1-bromoalkynes $\mathbf{2}$ in THF at low temperature to give diethyl 1-alkynylphosphonates $\mathbf{1 3}$ in fair to good yields (37-75\%) (Scheme 6). ${ }^{[32,33,34]}$ Usually, yields are improved upon further lowering the temperature and adding the bromoalkyne slowly. ${ }^{[32,34]}$ However, such precautions are not invariably necessary and fair yields $(20-63 \%)$ have been observed in the synthesis of a number of heterocycle-containing ethynylphosphonic esters upon reaction of the corresponding bromoacetylenic alcohols even in benzene at $80^{\circ} \mathrm{C} .{ }^{[35]}$ Likewise, the reaction between diethyl phosphite and 4-chloro-2-methyl-3-butyn-2-ol in dry $\mathrm{Et}_{2} \mathrm{O}$ at room temperature in the presence of a catalytic amount of $\mathrm{CuCl}$ and diethylamine reportedly gives good yields (60-72\%) of dialkyl 3-hydroxy-3-methyl-1-butynylphosphonate. ${ }^{[36]}$ Formation of dimethyl phenylethynylphosphonate in $68 \%$ yield has recently been described by treating alkynyl iodides with copper (I) dimethyl phosphite in a THF suspension under ultrasonic irradiation. ${ }^{[37]}$ Nevertheless, the Michaelis-Becker route does not always proceed cleanly and the dialkyl 1alkynylphosphonates $\mathbf{3}$ frequently contain undesired side products which are not easily removed. Given the difficulties associated with the use of bromoalkynes 2 , it is unsurprising that this reaction is used infrequently and that the general synthetic utility of the procedure remains to be proven. Haloalkynes are triphilic and the approach of anionic and neutral nucleophiles at the haloalkyne has been dicussed and evaluated in terms of the three sites. ${ }^{[24]}$

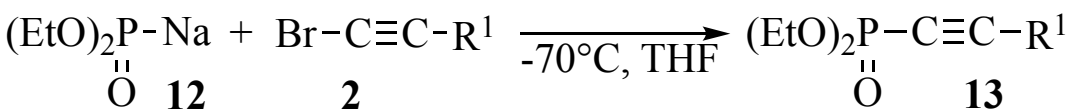

$$
\begin{aligned}
& \mathrm{R}^{1}=\mathrm{Me}, \mathrm{Et}, n \text {-Pr, } n \text {-Bu, } n \text {-Pent, } n \text {-Hex, Ph } \quad 37-75 \%
\end{aligned}
$$

\section{Scheme 6}


Propargyl bromide reacts with sodium diethyl phosphite 12 to give diethyl 1propynylphosphonate $\mathbf{1 8}(\mathrm{R}=\mathrm{Et})$. Unfortunately, irrespective of the reaction conditions, (sodium in refluxing $\mathrm{THF}^{[38]}$ or liquid ammonia, ${ }^{[31]}$ potassium carbonate in benzene at $70^{\circ} \mathrm{C}^{[39]}$ or potassium fluoride at $60^{\circ} \mathrm{C}$ without solvent ${ }^{[40]}$ ), complex mixtures containing diethyl 1-propynylphosphonate $18(\mathrm{R}=\mathrm{Et})$ and 2-propynylphosphonate and diethyl allenylphosphonate $\mathbf{1 7}\left(\mathrm{R}=\mathrm{Et}, \mathrm{R}^{1}=\mathrm{R}^{2}=\mathrm{R}^{3}=\right.$ $\mathrm{H})$ are obtained.

\section{Rearrangement and Isomerisation Reactions}

In 1962 three laboratories, in the Soviet Union ${ }^{[41]}$ and America, ${ }^{[42,43]}$ independently reported the rearrangement of dialkyl 2-alkynylphosphites $\mathbf{1 6}$ to dialkyl allenylphosphonates 17. Propargyl phosphites 16, readily obtained from propargyl alcohols 15 and dialkyl chlorophosphites 14 in $\mathrm{Et}_{2} \mathrm{O}$ at $0^{\circ} \mathrm{C}$ in the presence of $\mathrm{Et}_{3} \mathrm{~N}$ or pyridine, rearrange slowly upon standing at room temperature to produce excellent overall yields of readily isolable dialkyl allenylphosphonates 17 (Scheme 7). In ethereal solution at room temperature, the rearrangement stops at the stage of the allenylphosphonate 17. The particular ease with which the acetylenic-allenic rearrangement takes place is evidently due to a combination of the nucleophilic properties of the trivalent phosphorus atom and the rather electrophilic character of the triple bond. This rearrangement has been widely explored because the allenylphosphonates are particularly well suited for elaboration into enaminophosphonates by addition reactions at the allenic carbon atom.
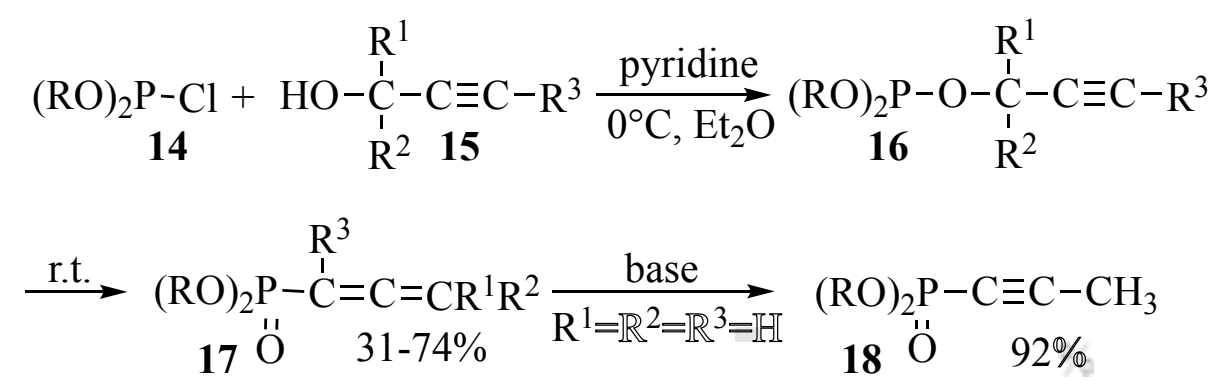

Scheme 7

The prototropic isomerisation of the allenylphosphonate $\mathbf{1 7}$ into the 1-propynylphosphonate 18 proceeds partially or completely under the influence of the organic base which is generally present in catalytic amounts in the reaction mixture. ${ }^{[4]}$ When pure dialkyl allenylphosphonates $\mathbf{1 7}$ were heated to $200^{\circ} \mathrm{C}$, they remained unchanged (apart from partial polymerisation). In the presence of a basic catalysts, sodium ethoxide, ${ }^{[45]} \mathrm{NaOH}^{[46]}$ and sodium hydride ${ }^{[47]}$ at room temperature or triethylamine ${ }^{[48-50]}$ and triethylphosphite ${ }^{[48]}$ at high temperature, they undergo prototropic isomerisation into dialkyl 1-propynylphosphonates 18 more or less readily. Thus, diethyl propadienylphosphonate $17\left(\mathrm{R}=\mathrm{Et}, \mathrm{R}^{1}=\mathrm{R}^{2}=\mathrm{R}^{3}=\mathrm{H}\right)$ was straightforwardly and almost completely isomerized into diethyl 1-propynylphosphonate $\mathbf{1 8}(\mathrm{R}=\mathrm{Et})$ in excellent yield $(92.5 \%)$. This method has allowed the preparation of a variety of dialkyl 1-propynylphosphonates $\mathbf{1 8}$ bearing different $\mathrm{R}$ groups at the phosphorus atom. The rearrangement of $\gamma$-substituted propargyl phosphites is accompanied by inversion of the unsaturated groups, but the rearrangement stops at the allenic isomers $\left(\mathrm{R}^{3} \neq \mathrm{H}\right)$ through the lack of a labile hydrogen atom at the carbon bound to the phosphoryl group. Similarly, dialkyl $\gamma, \gamma$-dimethylallenylphosphonate $17\left(R^{1}, R^{2} \neq H\right)$, which is thermodynamically more stable than the acetylenic isomer, does not undergo prototropic transformation in the presence of base. Even heating dialkyl $\gamma, \gamma$-dimethylallenylphosphonates in the presence of sodium ethoxide or triethylamine does not cause prototropic transformation, but instead provokes an intramolecular dimerization of the product, according to a kinetic study. Two variants of this rearrangement have been reported. One uses triethyl phosphite 4 instead of diethyl 
chlorophosphite $14(\mathrm{R}=\mathrm{Et}) .{ }^{[51]}$ Thus, in the presence of catalytic amount of para-toluenesulfonic acid, triethyl phosphite 4 reacts with propargyl alcool in DMF at room temperature to give a mixture of diethyl allenylphosphonate $17\left(\mathrm{R}=\mathrm{Et}, \mathrm{R}^{1}=\mathrm{R}^{2}=\mathrm{R}^{3}=\mathrm{H}\right)(51 \%)$ and 1propynylphosphonate $18(\mathrm{R}=\mathrm{Et})(14 \%)$. The second ${ }^{[52]}$ converts the allenylphosphonates $17\left(\mathrm{R}^{1}\right.$, $\mathrm{R}^{2} \neq \mathrm{H}, \mathrm{R}^{3}=\mathrm{H}$ ) into 1-alkynylphosphonates $\mathbf{1 8}$ in benzene with $46-50 \%$ yields by a photochemically allowed $[1,3 \mathrm{~s}]$-sigmatropic shift.

\section{B. Reactions at Electrophilic Phosphorus}

\section{Alkynylmagnesiums}

In the past, interest in the preparation of dialkyl 1-alkynylphosphonates 3 centred upon studies of nucleophilic addition to carbon-carbon triple bonds which were activated by phosphoryl groups. The parent ethynylphosphonate was prepared in 1960 by the reverse addition of stoichiometric ethynylmagnesium bromide to the appropriate dialkyl chlorophosphates in THF. ${ }^{[53]}$ The product was obtained in very low yield (12 to $25 \%$ ), presumably because of side reactions involving the relatively acidic alkynyl proton. The yields can be increased slightly ( 25 to $35 \%$ ) by the use of (toxic) dialkyl fluorophosphates. ${ }^{[54]}$ Despite advances in developing methodology for the elaboration of 1-alkynylphosphonates, the preparation of the parent ethynylphosphonates remained difficult for a prolonged period. Eventually, diethyl ethynylphosphonate $\mathbf{1 0}$ became easily accessible through reaction of a protected synthetic equivalent, trimethylsilylethyne 20, with methylmagnesium bromide in $\mathrm{Et}_{2} \mathrm{O}$ followed by addition to a solution of diethyl chlorophosphate 19 (SNP(V) reaction). ${ }^{[5]}$ The resulting diethyl trimethylsilylethynylphosphonate 9 was deprotected by hydrolysis with $10 \% \mathrm{Na}_{2} \mathrm{CO}_{3}$ to give the parent diethyl ethynylphosphonate $\mathbf{1 0}$ in a good overall yield of $74 \%$ (Scheme 8 ).
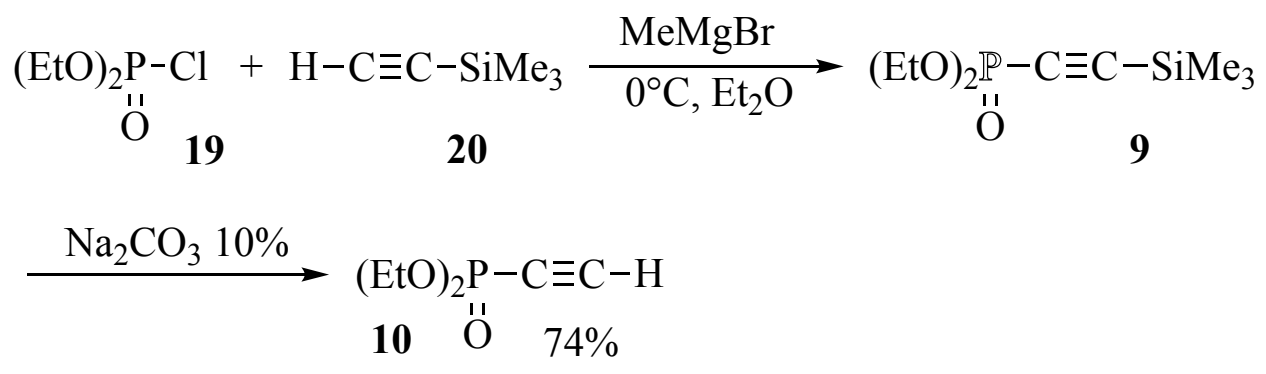

\section{Scheme 8}

The extension of this principle to higher homologues of acetylene gave superior results. These compounds were readily obtained from dialkyl or diphenyl chlorophosphates and the appropriate terminal alkynylmagnesium bromide, which was prepared in turn from the alkyne 21 and ethylmagnesium bromide in $\mathrm{Et}_{2} \mathrm{O}$ or THF (Scheme 9). ${ }^{[56]}$ The most widely employed phosphorus reagent is diethyl chlorophosphate $19(\mathrm{R}=\mathrm{Et})$ which is reacted with the alkynylmagnesium bromide through direct ${ }^{[33,34,57]}$ or inverse ${ }^{[56]}$ addition at $0^{\circ} \mathrm{C}$ in $\mathrm{Et}_{2} \mathrm{O}$ or at $-30^{\circ} \mathrm{C}$ in THF. This procedure has been successfully employed for the preparation of a variety of dialkyl 1-alkynylphosphonates 3 in fair to good yields (51 to 76\%), with the best results generally obtained using addition of the alkyne salt to the chlorophosphate. 


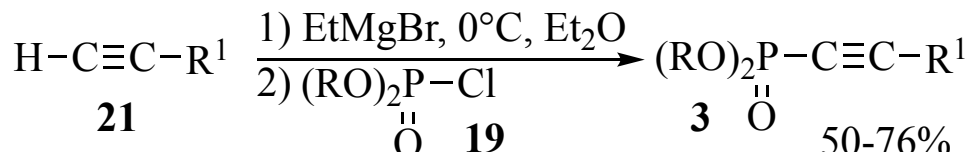

$$
\begin{aligned}
& \mathbb{R}=\mathbb{M e}, \mathbb{E t}, n-\mathbb{B u n}, \mathbb{P h} \\
& 50-76 \% \\
& \mathrm{R}^{1}=\mathbb{M e}
\end{aligned}
$$

Scheme 9

\section{2. with Alkynyllithiums}

Since lithium reagents are generally more reactive carbanion-equivalents than their Grignard counterparts, it might be expected that they would be able to condense more cleanly with chlorophosphates. Furthermore, the facile and quantitative generation of alkynyllithiums under low temperature conditions makes the use of lithium reagents for the generation of dialkyl 1alkynylphosphonates $\mathbf{3}$ a useful and especially attractive methodology which has been developed with simple and functionalized alkynes. Alkynes $\mathbf{2 1}$ were metallated with $n$-BuLi in THF solution at low temperature and the resultant lithium acetylides reacted with diethyl chlorophosphate $\mathbf{1 9}$ at the same temperature. This procedure minimizes side reactions and provides high and reproducible yields of diethyl 1-alkynylphosphonates 13 (Scheme 10). ${ }^{[58-66]}$ The synthesis of diethyl ethynyl phosphonate $\mathbf{1 0}$ has recently been described using lithium bis(diisopropylamino)boracetylide as the synthetic equivalent for lithium acetylide. After reaction with diethyl chlorophosphate $\mathbf{1 9}$ in THF at $-78^{\circ} \mathrm{C}$, the protected diethyl ethynylphosphonate was hydrolysed with a $3 \mathrm{M} \mathrm{HCl}$ solution to produce 10 in a good overall yield of $72 \%,{ }^{[67]}$ comparable with those previously obtained. ${ }^{[15,55]}$ Synthesis of 10 was also reported with an overall yield of $68 \%$ by a three-step synthesis including the reaction of lithium trimethylsilylacetylide with diethyl chlorophosphite $14(\mathrm{R}=\mathrm{Et})(83 \%)$ followed by oxidation with meta-chloroperbenzoic acid and deprotection with $\mathrm{KF}$ in EtOH $(82 \%) .{ }^{[68]}$

$$
\begin{aligned}
& \begin{array}{ccc}
\mathrm{H}-\mathrm{C} \equiv \mathrm{C}-\mathrm{R}^{1} & \frac{1) n-\mathrm{BuLi},-78^{\circ} \mathrm{C}, \mathrm{THF}}{2} & \left.(\mathrm{EtO})_{2} \mathrm{P}-\mathrm{C} \equiv \mathrm{C}\right)_{2} \mathrm{P}-\mathrm{Cl}-\mathrm{R}^{1} \\
\mathbf{2 1} & \mathbf{1 9} \stackrel{\mathrm{O}}{\mathbf{1 3}} \stackrel{\mathrm{O}}{\longrightarrow} & \mathbf{1 3}
\end{array} \\
& \mathbb{R}^{1}=n-\mathrm{Pr}, n-\mathrm{Bu}, t-\mathrm{Bu}_{2} n=\mathbb{H} \operatorname{ex}, \mathrm{BnOCH}_{2}, \mathrm{Me}_{2} \mathrm{C}(\mathrm{OH}) \text {, } \\
& \operatorname{THPO}\left(\mathbb{C H}_{2}\right)_{2}, \mathbb{P} \mathbb{h}, \mathbb{P} \mathbb{h}=\mathrm{S} . . .
\end{aligned}
$$

\section{Scheme 10}

The advantages of lithium acetylides over haloalkynes (Michaelis-Arbuzov or MichaelisBecker routes) have been clearly demonstrated in several comparable syntheses. In 1976 the preparation of diethyl 3,3-diethoxy-1-propynylphosphonate by condensation of 3,3-diethoxy-1lithio-1-propyne with diethyl chlorophosphate 19 at $-65^{\circ} \mathrm{C}$ was described. ${ }^{[58]}$ The product was easily purified and obtained in 70-80\% yield. By way of contrast, the reaction of 1-bromo-3,3diethoxy-1-propyne with potassium or sodium diethyl phosphite 12 (Michaelis-Becker reaction), gave only $30-40 \%$ yields of product from which impurities could not be easily removed by distillation. A comparison of the reaction sequences between magnesium and lithium acetylides, with respect to diethyl chlorophosphate $\mathbf{1 9}$, has also been undertaken under the same experimental conditions. It reveals that in all cases the use of lithium acetylides in place of the Grignard counterparts results in significantly higher yields. ${ }^{[34]}$

Dialkyl 1-alkynylphosphonates $\mathbf{3}$ can also be synthesized by the reactions of lithium tetraorganoaluminates with dialkyl chlorophosphates. However, the reaction of these lithium tetraorganoaluminates, prepared from $\mathrm{LiAlH}_{4}$ and the corresponding substituted alkynes in a 
pyridine medium, are often sluggish, requiring high temperatures $\left(105^{\circ} \mathrm{C}\right)$ and lengthy reaction times $(5 \mathrm{~h})$. However, they produce dialkyl 1-alkynylphosphonates 3 in good yields (60 to $80 \%) .{ }^{[69]}$

\section{C. $\beta$-Elimination Reactions.}

Since heteroatom-substituted vinylphosphonates such as enol phosphates and vinyl halides are masked acetylenic compounds, a variety of methods have been developed for their elaboration and subsequent use in the synthesis of 1 -alkynylphosphonates 3 . These $\beta$-eliminations usually have the leaving group $\beta$ - to the phosphoryl group, although cases where the leaving group is $\alpha$ - to the phosphorus centre are also known (Scheme 11).

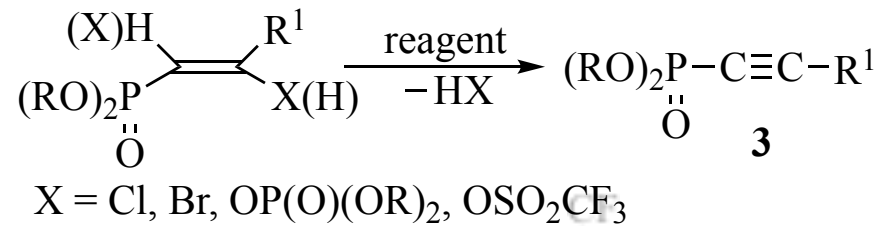

\section{Scheme 11}

The preparation of 1-alkynylphosphonates 3 by an appropriate $\beta$-elimination procedure was first recorded in 1957, when it was reported that the action of sodium ethoxide on diethyl 3diethylphosphonoisoprenyl phosphate $\mathbf{2 2}$ in refluxing EtOH led to diethyl 1-propynylphosphonate $18(\mathrm{R}=\mathrm{Et})$ in $69 \%$ yield (Scheme 12). ${ }^{[1,70]}$ The experimental conditions are crucial, and it has been shown that successful elimination of phosphate takes place to the exclusion of the ethanolysis reaction only at elevated temperature. At room temperature, the enol phosphate 22 was reported to undergo competing ethanolysis to triethyl phosphate and diethyl 2-oxopropylphosphonate. Given the drastic reaction conditions required for the subsequent conversion to 1-alkynylphosphonates, this method was rarely used and remained underdeveloped for a significant period of time. Fortunately, many efforts have been made to discover bases which might cause elimination of the phosphate from the enol without also bringing about isomerisation or hydrolysis. The development of a variety of milder alternative methods has led to the much more widespread adoption of this elimination sequence. ${ }^{[71]}$

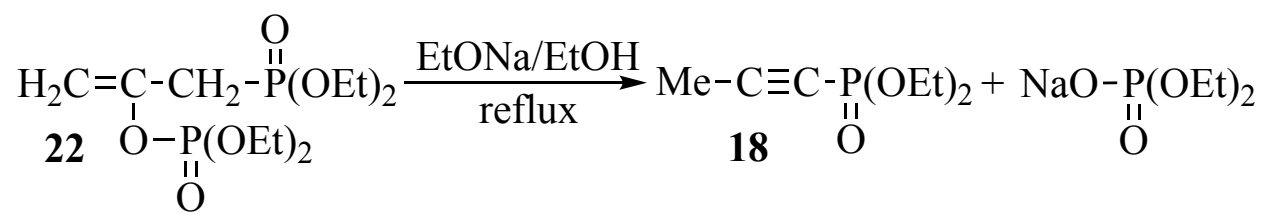

\section{Scheme 12}

Recently, the conversion of diethyl 2-oxoalkylphosphonates $\mathbf{2 3}$ to 1-alkynylphosphonates $\mathbf{1 3}$ via transient enol phosphates $\mathbf{2 4}$ has been shown to occur in good yields. Thus, treatment of diethyl 2-oxoalkylphosphonates $\mathbf{2 3}$ with $\mathrm{NaH}$ in THF followed by addition of diethyl chlorophosphate 19 gave the enol phosphate 24. The $\beta$-elimination reaction from the enol phosphate was carried out at low temperature using $t$-BuOK. The reaction proceeds satisfactorily in 72 to $95 \%$ overall yield with 2-oxoalkylphosphonates (Scheme 13$).{ }^{[72]}$ In case of long chain substituent $\left(\mathbf{2 4}, \mathrm{R}^{1}=\mathrm{Et}\right.$ ), the product underwent a prototropic isomerisation to give a mixture of diethyl 1-butynylphosphonate $13\left(\mathrm{R}^{1}=\right.$ Et) and 2-butynylphosphonate. 


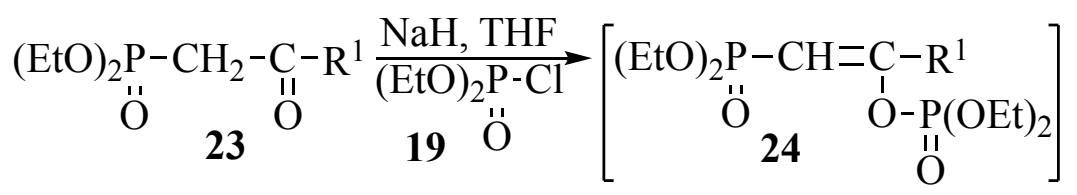

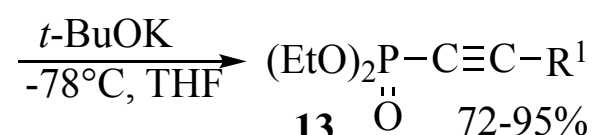

$\mathrm{R}^{1}=\mathrm{Me}, i-\mathrm{Pr}, t-\mathrm{Bu}, \mathrm{Ph}$

\section{Scheme 13}

This approach has been adapted to the preparation of dialkyl fluoro-1-alkynylphosphonates in $65-80 \%$ yields through trifluoromethanesulfonation of the dialkyl trifluoro-2hydroxypropenylphosphonate using trifluoromethanesulfonic anhydride in the presence of diisopropylethylamine (3 eq.). ${ }^{[73]}$

Procedures for the conversion of enol phosphates into the corresponding alkynes involve strongly basic conditions, but several milder methods have been reported in the related case of vinyl halides, which are ideal precursors for triple bond generation by a $\beta$-elimination reaction. Two complementary approaches for the synthesis of 1-alkynylphosphonates $\mathbf{3}$ have been developed, one using simple dehydrochlorination of 2-chlorovinylphosphonates and the other by dehydrochlorination with subsequent double bond isomerisation of 2-haloallylphosphonates. For example, dialkyl 2-chlorovinylphosphonates undergo a $\beta$-elimination on heating with an equimolecular amount of $\mathrm{KOH}$ in absolute $\mathrm{EtOH}$ to give the corresponding 1-alkynylphosphonates 3 in $73-85 \%$ yields. ${ }^{[74,75]}$ Similarly, by the judicious selection of base, 2-haloallylphosphonates, obtained by a Michaelis-Arbuzov reaction from 2,3-dihalo-1-propenes and trialkyl phosphites 1, may be converted to allenyl- 17 or 1-propynylphosphonates 18. Thus, treatment of diethyl 2bromopropenylphosphonate $\mathbf{2 5}$ with ethylmagnesium bromide in $\mathrm{Et}_{2} \mathrm{O}$ at room temperature produced the diethyl allenylphosphonate $17\left(\mathrm{R}=\mathrm{Et}, \mathrm{R}^{1}=\mathrm{R}^{2}=\mathrm{R}^{3}=\mathrm{H}\right)$ in $45 \%$ yield while treatment with the more basic $\mathrm{NaH}$ in the same conditions gave the diethyl 1-propynylphosphonate $18(\mathrm{R}=\mathrm{Et})$ in $90 \%$ yield (Scheme 14). ${ }^{[47 \mathrm{~b}]}$ Similarly, treatment of diisopropyl 2chloroallylphosphonate with $10 \%$ aqueous methanolic sodium carbonate at room temperature provoked facile dehydrochlorination with subsequent double bond isomerisation to afford diisopropyl 1-propynylphosphonate $18\left(\mathrm{R}=i\right.$-Pr) in essentially quantitative yields. ${ }^{[76]}$ In the case of 2-chlorovinylphosphonic dichlorides, the conversion into 1-alkynylphosphonic dichlorides is effected by triethylamine in refluxing benzene. ${ }^{[77]}$

$$
\begin{aligned}
& \begin{array}{cccc}
(\mathrm{RO})_{3} \mathrm{P} & +\mathrm{Br}-\mathrm{CH}_{2}-\mathrm{C}=\mathrm{CH}_{2} \\
\mathbf{4} & \mathrm{Br} & (\mathrm{RO})_{2} & \mathrm{P}-\mathrm{CH}_{2}-\underset{1}{\mathrm{C}}=\mathrm{CH}_{2} \\
& \mathbf{2 5} \mathrm{O} & \mathrm{Br}
\end{array} \\
& \mathrm{R}=\mathrm{Et}, i-\mathrm{Pr}
\end{aligned}
$$

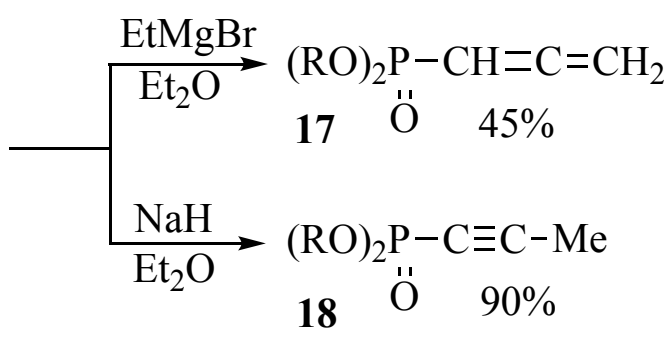

\section{Scheme 14}

Another procedure for the synthesis of dialkyl 1-propynylphosphonate $\mathbf{1 8}$ is based upon a simple dehydrochlorination of dialkyl 1-chloro-cis-propenylphosphonate or a double dehydrochlorination-detosylation of dialkyl 1-chloro-2-mesityloxypropylphosphonates. The 
reaction conditions for the elimination reaction, which involves alkali metal hydroxides or amides in $\mathrm{MeOH}$ at room temperature, are relatively mild. ${ }^{[78]}$

An even gentler method for the dehydrochlorination of the diethyl 2-bromopropenoate $\mathbf{2 6}$ to 2-propynoate 27 employs triethylamine in refluxing $\mathrm{Et}_{2} \mathrm{O}^{[79]}$ or $\mathrm{DBU}$ in $\mathrm{Et}_{2} \mathrm{O}$ at low temperature. ${ }^{[80]}$ The results are better with the former reagent (Scheme 15).

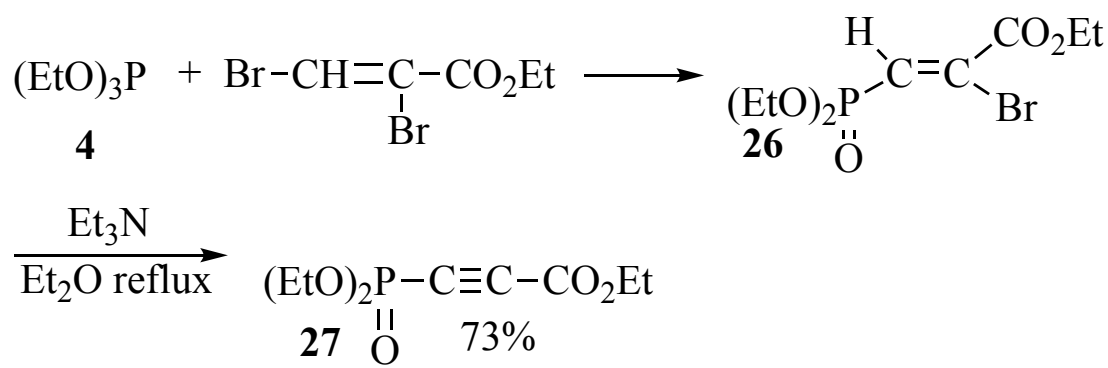

\section{Scheme 15}

Diethyl trichloromethylphosphonate $\mathbf{2 8}$ appears to be a very useful reagent for the generation of a triple bond from an $\alpha$-chlorovinylphosphonate $\mathbf{3 0}$. The lithiated $\beta$ hydroxyphosphonates, which are obtained by the addition of the diethyl 1lithiochloro(trimethylsilyl)methylphosphonate $\mathbf{2 9}$ to aromatic or heteroaromatic aldehydes, undergo a Peterson reaction to give $\alpha$-chlorovinylphosphonates $\mathbf{3 2}$ as a mixture of $Z$ and $E$ isomers. These latter compounds readily undergo dehydrochlorination at low temperature with LiHMDS or LDA to produce high overall yields (89-96\%) of a wide range of novel diethyl 1-alkynylphosphonates 13 bearing an aromatic or heteroaromatic ring in the $\beta$ position (Scheme 16). ${ }^{[81]}$
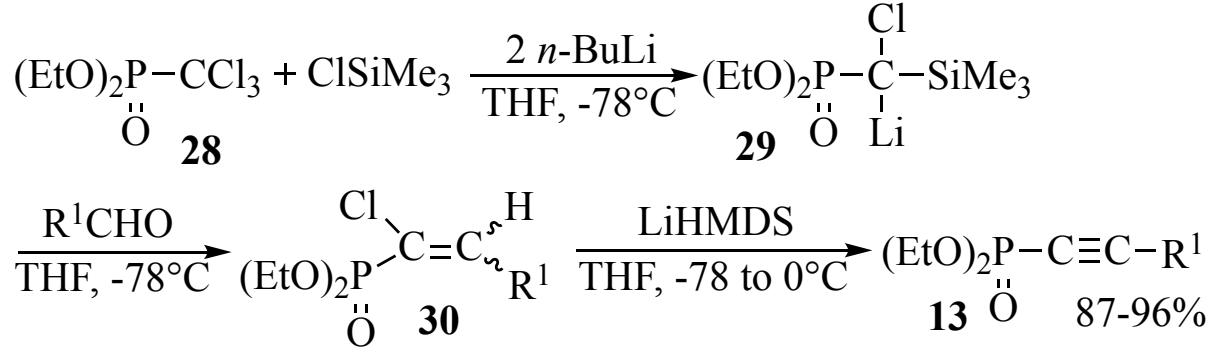

$\mathrm{R}^{1}=$ phenyl, pyridyl, furyl, thienyl, pyrrolyl

\section{Scheme 16}

An intramolecular Wittig reaction has been successfully applied to the synthesis of 1$\begin{array}{lllll}\text { alkynylphosphonates } & \mathbf{3 4} & \text { through } & \text { pyrolysis } & \text { of }\end{array}$ diphenoxyphosphorylmethylenetriphenylphosphoranes 33. The latter was prepared by a transylidation reaction between the phosphonium salt of $\mathbf{3 3}$ and the ylide 31. In general, this phosphonium salt was obtained by action of the perfluoroacetyl chloride $\mathbf{3 2}$ in excess on the ylide 31 at $50{ }^{\circ} \mathrm{C}$ in benzene. Pyrolysis of the resulting $\beta$-ketoylids 33 under nitrogen at reduced pressure $\left(220^{\circ} \mathrm{C} / 10^{-5}\right.$ torr) then produces diphenyl perfluoroalkynylphosphonates 34 in good yield (78$85 \%)\left(\right.$ Scheme 17). ${ }^{[82]}$ 


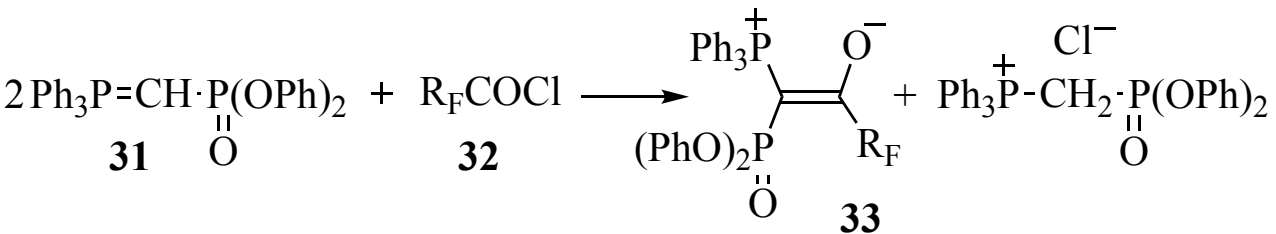

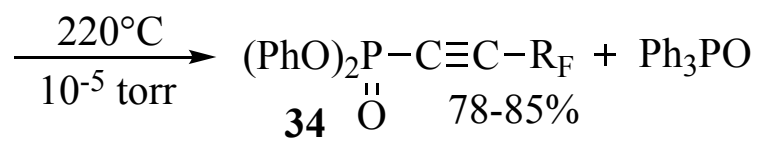

$$
\begin{aligned}
& \mathrm{R}_{\mathrm{F}}=\mathrm{CF}_{3}, \mathrm{CF}_{3} \mathrm{CF}_{2}, n-\mathrm{C}_{3} \mathbb{F}_{7}
\end{aligned}
$$

\section{Scheme 17}

The thermal syn-elimination of selenoxide from $\alpha$-phosphorylvinyl selenoxides in refluxing benzene solution to give 1-alkynylphosphonates has also been reported. However, the thermolysis reaction, which eliminates selenium-containing by-products, only occurs with the $E$ isomers of $\alpha$ phosphorylvinyl selenoxides. ${ }^{[83]}$

\section{Chemistry.}

\section{A. Reactions of the Triple Bond}

\section{Reduction}

Partial reduction of the triple bond has been used for the selective conversion of 1alkynylphosphonates into cis-1-alkenylphosphonates. The first racemic synthesis of the antibiotic fosfomycin 39 in 1969 serves as an illustration. The methodology was based on the stereospecific reduction of dibutyl 1-propynylphosphonate $\mathbf{3 7}$ into dibutyl Z-1-propenylphosphonate $\mathbf{3 8}$ using the Lindlar catalyst $\left(\mathrm{Pd} / \mathrm{CaCO}_{3}\right.$ poisoned with lead acetate) in $\mathrm{MeOH} .{ }^{[66,84,]}$ Dibutyl 1propynylphosphonate 37 was obtained in reasonable yield $(49 \%)$ by reaction of propynylmagnesium bromide 35 with dibutyl chlorophosphate 36 in a $\mathrm{C}_{6} \mathrm{H}_{6}$ / THF solution (section B. 1) (Scheme 18). ${ }^{[84,85]}$
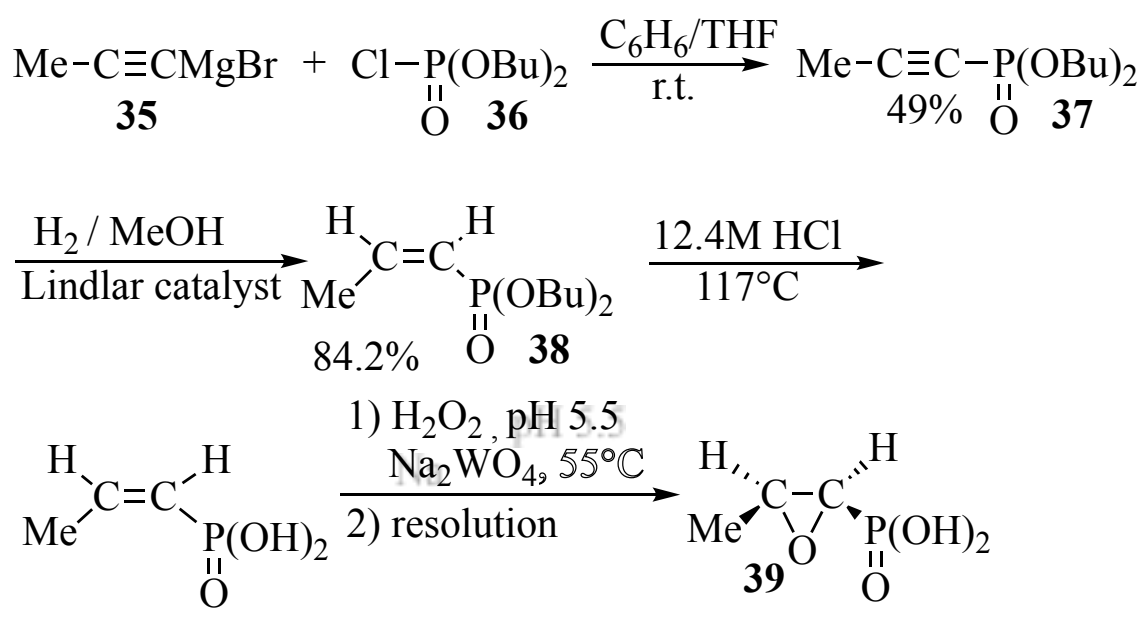

\section{Scheme 18}

Unfortunately, the subsequent step using the Lindlar catalyst met with little success and nonstereoselective partial reduction of the triple bond was observed. ${ }^{[86]}$ It was reported that most catalytic hydrogenations of 1-alkynylphosphonates 3 in EtOH using 5\% $\mathrm{Pd} / \mathrm{CaCO}_{3}$ poisoned with 
quinoline gave mixtures comprising cis- and trans-1-alkenylphosphonate and starting material, from which the predominant cis isomer was isolated. ${ }^{[86,87]}$ On the basis of these results a systematic analysis of the relative formation of these three products from the reduction of tetraethyl acetylenediphosphonate 7 was undertaken using a range of catalysts $\left(\mathrm{Pd} / \mathrm{CaCO}_{3}\right.$, Lindlar, $\mathrm{Pd} /$ $\left.\mathrm{BaSO}_{4} / \mathrm{Pb}, \mathrm{Pd} / \mathrm{BaSO}_{4}, \mathrm{Pd} / \mathrm{BaCO}_{3}, \mathrm{Pd} / \mathrm{SrCO}_{3}\right) .{ }^{[88]}$ It appeared that quinoline-poisoned $\mathrm{Pd} /$ $\mathrm{BaSO}_{4}$ was superior to the other catalysts for the selective reduction of the alkyne to the desired cisalkenediphosphonate. Hydrogenation of di-n-butyl-3-hydroxy-1-propynylphosphonate using Pd / $\mathrm{BaSO}_{4}$ and quinoline in $\mathrm{MeOH}$ afforded the desired cis-olefin in 95\% yield. ${ }^{[89]}$ Similarly, diethyl 4methanesulfonyl-1-butenylphosphonate was partially hydrogenated with $63 \%$ yield using $\mathrm{Pd} /$ $\mathrm{BaSO}_{4}$ in THF / pyridine. ${ }^{[90]}$

\section{Hydration}

The effectiveness of 1-alkynylphosphonates 3 as acetonyl equivalents for the preparation of 2-oxoalkylphosphonates has been long established. Since 2-oxoalkylphosphonates themselves are versatile synthetic intermediates, especially as the reagents of choice for promoting a number of Horner-Wadsworth-Emmons cyclisation reactions, procedures that effect the direct conversion of dialkyl 1-alkynylphosphonates 3 into 2-oxoalkylphosphonates are of special importance. The procedure for the hydration of 1-alkynylphosphonates 3 has remained unchanged since the first report in 1966 (Scheme 19). ${ }^{[32]}$ Thus, treatment of diethyl 1-alkynylphosphonates 13 with aqueous $\mathrm{H}_{2} \mathrm{SO}_{4}$ in $\mathrm{MeOH}$ in the presence of $\mathrm{HgSO}_{4}$ gave, after reflux for $15 \mathrm{~h}^{[32]}$ or at room temperature for $48 \mathrm{~h},{ }^{[60,91]}$ a quantitative yield of pure diethyl 2-oxoalkylphosphonates 23 . In all cases studied, the acetylenic phosphonates were transformed without formation of the isomeric ketophosphonates. When the phosphorus substrate contains an acid sensitive group, the hydration reaction can be performed in good yield at room temperature in aqueous THF in the presence of $\mathrm{HgCl}_{2}(1$ eq. $)$ and pyridine $(1.5$ eq. $) .{ }^{[92]}$

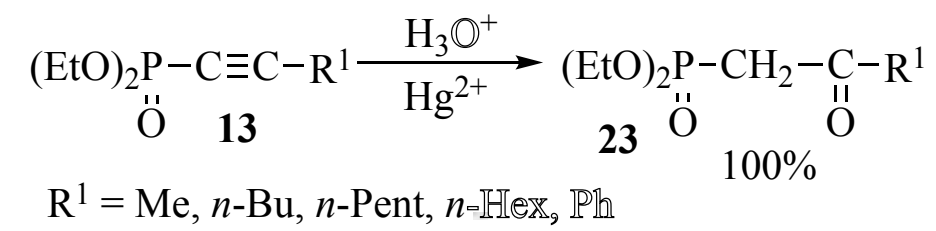

\section{Scheme 19}

Sensitive enyne phosphonates have been converted into $\gamma, \delta$-ethylene- $\beta$-ketophosphonates in reasonable yields (25-70\%) by treatment with a mixture of $\mathrm{HgO} / \mathrm{ClCH}_{2} \mathrm{CO}_{2} \mathrm{H} / \mathrm{BF}_{3} \cdot \mathrm{Et}_{2} \mathrm{O} / \mathrm{ROH}$ in refluxing EtOH. ${ }^{[93]}$

\section{Cycloaddition Reactions}

\section{a. $[2+2]$}

The cycloaddition of enamines $\mathbf{4 0}$ with activated alkynes, such as dimethyl acetylenedicarboxylate, is reported to occur at room temperature. In contrast, the less reactive diethyl 1-alkynylphosphonates $\mathbf{1 3}$ require reaction temperatures of at least $85^{\circ} \mathrm{C}$ to permit cycloaddition. Under such conditions, spontaneous ring opening of the thermally unstable cyclobutene intermediate $\mathbf{4 1}$ affords the ring enlarged product $\mathbf{4 2}$. Acid hydrolysis of the product enamine gave the unsaturated $\beta$-ketophosphonate $\mathbf{4 3}$ (Scheme 20). ${ }^{[63]}$ The best results for the 
cycloaddition were obtained with rigorous exclusion of moisture and with temperatures held below $100^{\circ} \mathrm{C}$. Reaction times varied from $24 \mathrm{~h}\left(\mathrm{R}^{1}=\mathrm{H}\right)$ to 8 days $\left(\mathrm{R}^{1}=\mathrm{CH}_{2} \mathrm{OMe}\right) .{ }^{[63]}$

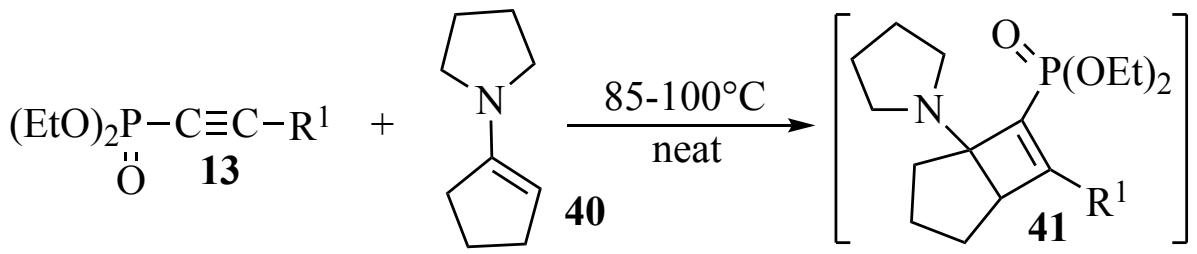

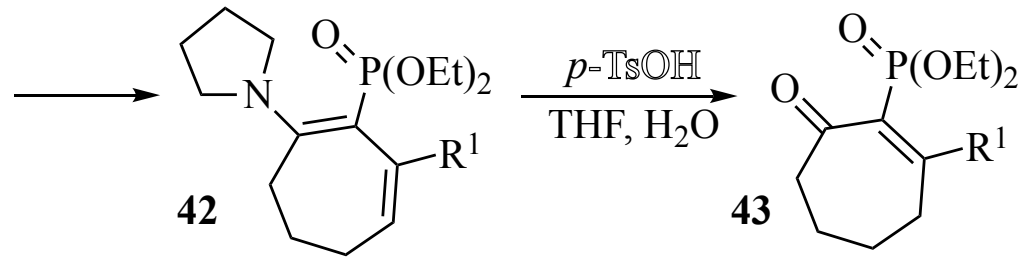

$\mathrm{R}^{1}=\mathrm{H}, n-\mathrm{Pr}, \mathrm{CH}_{2} \mathrm{OMe}, \mathbb{P h}$

Scheme 20

The reaction must be carefully controlled in order to optimise the yield. Cycloadditions with substituted diethyl 1-alkynylphosphonates $\mathbf{1 3}$ are less satisfactory, for example $\mathrm{R}^{1}=\mathrm{H}$, yield $=77 \%$ and $\mathrm{R}^{1}=\mathrm{Ph}$, yield $=17 \%($ for $\mathrm{n}=1)$.

\section{b. $[3+2]$}

Cycloadditions of diazo- and azidocompounds with acetylenes constitute a well-established method for the synthesis of pyrazoles and triazoles. Addition of diazomethane to ethynylphosphonates provides a convenient method for synthesizing phosphonopyrazoles. ${ }^{[54,94]}$ Thus, diisopropyl ethynylphosphonate $\mathbf{4 4}$ reacted smoothly with an excess of diazomethane to give the 1-methyl-5-phosphonopyrazole 45 in 28\% yield, with the diazomethane acting as an $N$ methylation reagent for the first-formed phosphonopyrazole (Scheme 21). ${ }^{[54]}$ The tetramethyl acetylenediphosphonate $\mathbf{5 4}$ reacts spontaneously with diazomethane in cooled $\mathrm{Et}_{2} \mathrm{O}$ to give the 4,5diphosphonopyrazole 46 in $95 \%$ yield (Figure 1). ${ }^{[1]}$

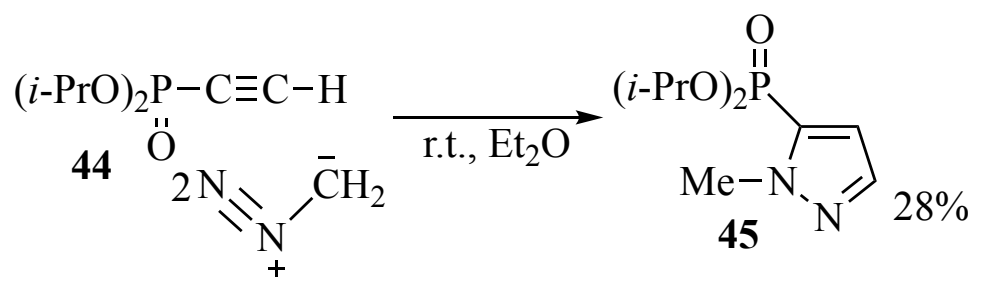

\section{Scheme 21}

Cycloadditions of ethyl diazoacetate with 1-alkynylphosphonates $\mathbf{3}$ have also been studied. ${ }^{[95,96,97]}$ The data indicate that the cycloaddition of ethyl diazoacetate with diethyl ethynyl10, 1-propynylphosphonates $18(\mathrm{R}=\mathrm{Et})$ and perfluoroalkynylphosphonates 34 , wherein the imino group participates in a strong intermolecular hydrogen bond, gives tautomeric pyrazolylphosphonates 47 in $58-92 \%$ yields, as a mixture of regioisomers. Because of its instability, the intermediate $3 H$-pyrazole is isomerized rapidly to the $1 H$-pyrazole. The electronaccepting ethoxycarbonyl group, by conferring acidic character on the $\mathrm{C}_{3}-\mathrm{H}$ bond, facilitates this 
aromatisation to give the $1 H$-pyrazole 47. A study of the influence of the phosphorus substituent $(\mathrm{Cl}, \mathrm{EtO}, i-\mathrm{PrO}, n-\mathrm{BuO}, \mathrm{Et}, \mathrm{Ph})$ upon the cycloaddition reaction has appeared. Ethyl diazoacetate reacts most easily with 1-alkynylphosphonates bearing dichloro substituents at phosphorus, while the reaction with diethyl substituents requires more severe conditions. ${ }^{[95]}$

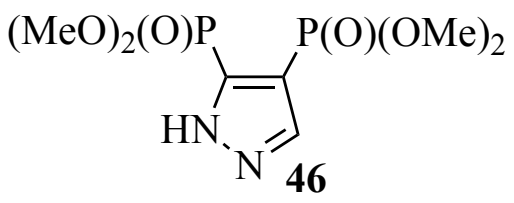

Figure 1

$$
\mathrm{R}^{1}=\mathrm{H}, \mathrm{Me}, \mathrm{R}_{\mathrm{F}}
$$

Other 1,3-dipoles such as $C$-aryl- $N$-phenylnitrones ${ }^{[98]}$ para-substituted phenylazides,${ }^{[99,100]}$ azidoalkylcarboxylates ${ }^{[97,101]}$ and azidoalkylphosphonates, ${ }^{[102]} C$-substituted- $N$-arylnitrilimines, ${ }^{[103]}$ para-substituted benzonitrile oxide ${ }^{[57,97]}$ and $N$-phenylsydnone ${ }^{[104]}$ react with diethyl 1alkynylphosphonates 13. They gave respectively, 5-isoxazolinephosphonates 48 in $42-72 \%$ yield, ${ }^{[98]} 1$-aryl-4-triazolylphosphonates $49,{ }^{[95-97]} 1$-carboxyalkyl- ${ }^{[97,101]}$ and 1-phosphonoalkyl-4triazolylphosphonates ${ }^{[102]} 4$ - or 5-pyrazolylphosphonates $\mathbf{5 0}$ and $\mathbf{5 1},{ }^{[103]}$ 4-isoxazolinephosphonate in $80-92 \%$ yields $^{[57,97]}$ and 3-pyrazolylphosphonates in $53 \%$ yield $^{[104]}$ (Figure 2). The reactivity of phosphorylated propynes and the chemo- and regioselectivity of these reactions is controlled both by donor-acceptor interactions between the reactants and the steric requirements of their substituents.<smiles>CCOC(=O)C1=C(C)C(CCOC)N(c2ccccc2)O1</smiles><smiles>[Y]CCn1nnc([PH2]OCC)c1[R]</smiles>

49<smiles>CCOC(OCC)c1[nH]nc(-c2ccccc2)c1C</smiles><smiles>CCOC(OCC)c1c(-c2ccccc2)nn([Al]([AlH2])c2ccccc2)c1C</smiles>

Figure 2

\section{c. $[4+2]$}

The facile Diels-Alder reaction of dialkyl 1-alkynylphosphonates $\mathbf{3}$ means that organophosphorus-substituted acetylenes are potentially useful precursors for introducing organophosphorus substituents into diverse organic structures. This chemistry has been developed mainly with dienophiles such as ethynyl- ${ }^{[61]}$ haloethynyl- ${ }^{[10,11]}$ formylethynyl- ${ }^{[86]}$ sulfonylethynyl${ }^{[61]}$ sulfoxylethynyl-, ${ }^{[61]}$ phenylethynylphosphonates ${ }^{[105]}$ and acetylenebisphosphonates. ${ }^{[1,19]}$ Only one activating group on the alkyne is necessary for the cycloaddition to occur and the monophosphorylated acetylene reacts as readily as the diphosphorylated. Dienes such as isoprene ${ }^{[86]} \quad 2,3$-dimethyl-1,3-butadiene, ${ }^{[10]}$ cyclopentadiene, ${ }^{[11]} 1,3$-cyclohexadiene, ${ }^{[10]}$ anthracene, ${ }^{[61]}$ 9-methylanthracene ${ }^{[61]} 1$-phenyl-3,4-dimethylphosphole ${ }^{[105]}$ and $\alpha$-pyrone ${ }^{[19]}$ have been employed (Figure 3). 

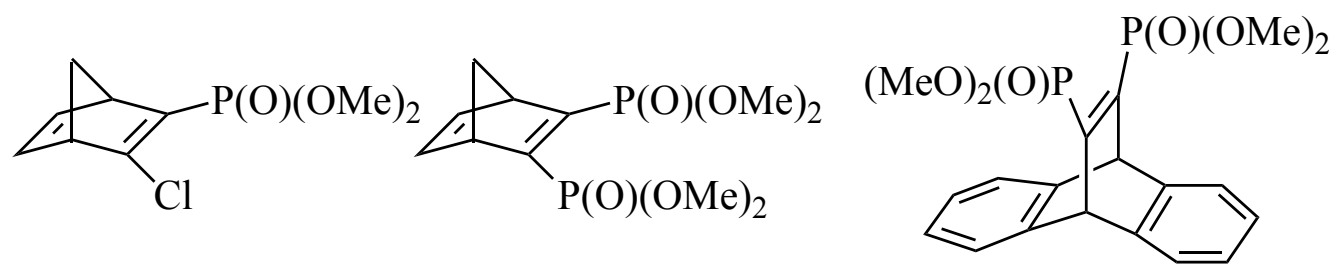

Figure 3

The reactions may be conducted with, or more rarely without, a solvent. Benzene, toluene, or xylene at reflux are generally preferred and yields are usually good to excellent (65-93\%). The strong points of this synthetic procedure are clearly illustrated by the preparation of orthophenylenediphosphonate 54 in $93 \%$ yield (Scheme 22) ${ }^{[11]}$ from the reaction of 52 with 1,3cyclohexadiene 53 at $150^{\circ} \mathrm{C}$. For 9-methylanthracene, the reaction is highly selective and the cycloadduct contains only one isomer. ${ }^{[61]}$ The Diels-Alder reaction has been investigated in particular detail for sulphonylethynyl- and sulphoxylethynylphosphonates. ${ }^{[61]}$

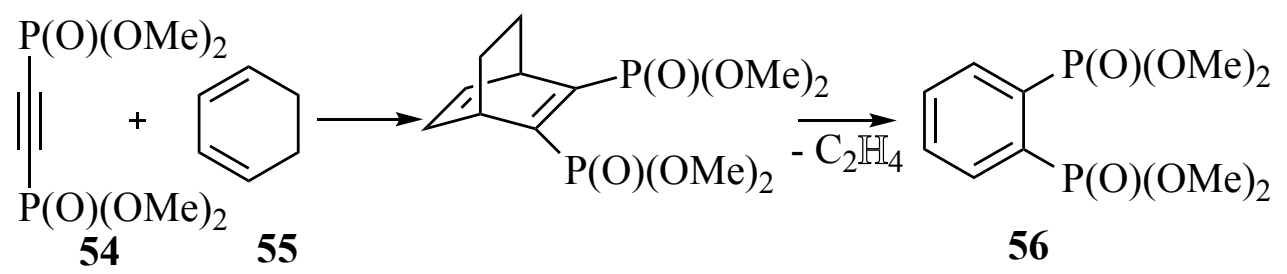

Scheme 22

\section{d. Intramolecular Ene Reaction}

Depending upon the position of unsaturation, two different examples of intramolecular enetype reactions of enynes have been described. The first involves an intramolecular ene reaction of 1,6-enynes whose triple and double bonds comprise part of the same phosphorus substituent. Catalytic amounts of $\mathrm{Pd}(\mathrm{OAc})_{2}$ in the presence of $\mathrm{Ph}_{3} \mathrm{P}$ were used for the cyclisation. In toluene, slight heating $\left(60^{\circ} \mathrm{C}\right)$ for $4 \mathrm{~h}$ allowed complete reaction at a reasonable rate. Comparative tests showed that $\mathrm{Pd}(\mathrm{OAc})_{2}$ and $\mathrm{Ph}_{3} \mathrm{P}$ gave the best results among all the ligands employed. The yield of isolated methylcyclopentylidenephosphonate from a gram-scale reaction was $68 \%$. ${ }^{[62]}$

In the second reaction type, the ene and yne functionalities form part of two different phosphorus substituents (Scheme 23). The 1-alkynylphosphonate 55 underwent facile $\mathrm{Pd}(\mathrm{OAc})_{2}$ $\mathrm{LiCl}$ catalyzed cyclisation to give the oxaphospholanes 56 in good (77-89\%) yield but with low stereoselectivity ( $Z$ to $E$ ratios at the exo double bonds being approximately $60 / 40) .{ }^{[106]}$<smiles>[R]C#CP(=O)(OCC)OC/C=C/CCl</smiles>

\section{Scheme 23}

$\mathrm{AcOH}$ appears to be the best solvent, and the reaction does not proceed particularly well in $\mathrm{MeCN}, \mathrm{C}_{6} \mathrm{H}_{6}, \mathrm{EtOH}, \mathrm{THF}$ or $\mathrm{MeNO}_{2}$. The mechanism may involve cis- and trans- 
halogenopalladation of the triple bond, followed by insertion of the double bond into the $\mathrm{C}-\mathrm{Pd}$ bond followed by dehalopalladation to regenerate the catalyst. ${ }^{[106]}$

\section{Addition Reactions}

Three types of compounds, dialkyl ethynyl-, 1-alkynylphosphonates and 2chloroethynylphosphonates predominate within this category. Treatment of diethyl ethynylphosphonates $\mathbf{1 0}$ with chlorine in $\mathrm{CCl}_{4}{ }^{[9]}$ or bromine in $\mathrm{Et}_{2} \mathrm{O}^{[54]}$ leads to the formation of isomeric $E$ and $Z$-1,2-dihalovinylphosphonates in good yields. By selecting the correct conditions, either one or two molecules of EtOH can be added across the triple bond in the presence of EtONa to give, respectively, the 2-ethoxyvinylphosphonates and 2,2-diethoxyethylphosphonates. ${ }^{[54]}$ The related addition of EtSH gives 2-ethylthiovinylphosphonates, but the product is most conveniently obtained as a mixture of both isomers by adding the ethynyl compound to an excess of the thiol containing dissolved sodium. ${ }^{[54]}$ Recently, an efficient stereoselective hydrohalogenation reaction of dialkyl ethynylphosphonates affording the Z-halovinylphosphonates has been reported. ${ }^{[107]}$ Thus, heating diethyl ethynylphosphonate 10 with $\mathrm{LiI}$ in $\mathrm{AcOH}$ at $70^{\circ} \mathrm{C}$ for $14 \mathrm{~h}$ affords diethyl 2iodovinylphosphonate as the sole product in $85 \%$ yield. The corresponding bromo and chloro analogues were also prepared in high regiostereoselectivity, although in lower yields: $50 \%$ for the bromo and 30\% for the chloro derivatives. ${ }^{[107]}$ Michael addition to the triple bond has also been utilized to prepare alkenylphosphonic acids analogues of nucleosides. Thus, the conjugate addition of heterocyclic bases (adenine, uracil, cytosine, thymine) to diethyl ethynylphosphonate $\mathbf{1 0}$ has been investigated in depth. Using $t$-BuOK as base, 18 -crown-6 as catalyst, MeCN or DMF as solvents, the alkylation of heterocyclic bases led to two isomers $(Z$ and $E)$ in moderate yields $(32-41 \%)$ in approximate $Z / E>1$ ratio. The yields are improved to $70-80 \%$ using $\mathrm{K}_{2} \mathrm{CO}_{3}$ as base in DMF at room temperature. ${ }^{[16,108]}$

A relatively general procedure for the conversion of diethyl 1-alkynylphosphonates $\mathbf{1 3}$ to diethyl 2-oxoalkylphosphonates 23 using enaminophosphonates has been developed. When 1alkynylphosphonates $\mathbf{1 3}$ were heated under reflux with a ten molar excess of primary or secondary amine, enaminophosphonates were produced in fair to good yields. ${ }^{[109]}$ The addition to the triple bond was complete in $20 \mathrm{~h}$ for $\mathrm{Et}_{2} \mathrm{NH}^{[110]}$ and in 3-5 days for $n-\mathrm{BuNH}_{2}{ }^{[109]}$ The subsequent hydrolysis of the resulting enaminophosphonates with oxalic acid in a two phase system at room temperature affords the diethyl 2-oxoalkylphosphonates 23 in excellent yields (76-94\%). ${ }^{[109]}$ Dialkyl 1-alkynylphosphonates $\mathbf{3}$ are capable of adding other nucleophilic reagents, in particular diethyl phosphite ${ }^{[11]}$ and ethyl mercaptan, ${ }^{[12]}$ forming products of the addition of one or two molecules of the reagent at the triple bond. ${ }^{[111]}$ For example, 1-tert-butylacetylenephosphonate is subject to a nucleophilic attack by the sodium diethyl phosphite $\mathbf{1 2}$ in THF at room temperature for $24 \mathrm{~h}$ to give a triphosphonate in good yield. ${ }^{[29]}$ A decrease in the activity of sodium diethyl phosphite 12 was observed in ethanolic solutions. The triple bond is attacked by the sodium diethyl phosphite 12 in the $\beta$ position with respect to the bulky group and not $\beta$ to the phosphoryl group. Steric hindrance predominates over the electronic directing influence of the phosphoryl group. The addition of mercaptans proceeds more readily and in the presence of excess mercaptans, addition results in the formation of only 2,2-dithioalkoxypropanes. ${ }^{[12]}$ By way of contrast, heating equimolar amounts of dialkyl 1-propynylphosphonates 3 with alcohols in the presence of sodium alkoxide at $60-70^{\circ} \mathrm{C}$ leads to only one addition product : 2-alkoxypropene. ${ }^{[12]}$ In the reaction of benzenesulfenyl chloride with diethyl 1-propynylphosphonate $18(\mathrm{R}=\mathrm{Et})$, the two regioisomeric adducts showing an $E$ arrangement of the phenylthio group and the chlorine atom relative to the double bond were obtained. ${ }^{[113]}$ Alkyl or aryl chalcogenate (S, Se, Te) anions add to diethyl 1alkynylphosphonates 13 to give diethyl 2-chalcogenylvinylphosphonates in satisfactory yields (26$70 \%$ ). The reaction is stereoselective, giving predominantly or exclusively the $Z$ stereoisomer. ${ }^{[114]}$ Diethyl 1-alkynylphosphonates $\mathbf{1 3}$ react readily with an excess of alkyl- or arylmagnesium halides 
in the presence of $\mathrm{CuCl}$ at $-30^{\circ} \mathrm{C}$ in $\mathrm{Et}_{2} \mathrm{O}$ to provide high yields $(75-95 \%)$ of $\beta$-alkylated or arylated diethyl 1-alkenylphosphonates. The addition is highly stereoselective producing almost exclusively the product of cis addition. Stoichiometric lithium dialkyl- or diarylcuprates can also react with $\mathbf{1 3}$ in $\mathrm{Et}_{2} \mathrm{O}$ at low temperature to produce 1-alkenylphosphonates in high regio- ans stereoselectivity. The intermediate alkenylcuprates are particularly suited to provide trisubstituted diethyl 1alkenylphosphonates by reaction with a wide range of electrophiles. ${ }^{[87]}$

The phosphorus-containing ynamines have been prepared through the reaction of diethyl 2chloroethynylphosphonates 6 with dialkylamines. ${ }^{[115]}$ Some of these compounds were also prepared by heating 6 with trimethylamine $(100 \%$ excess $)$ in a sealed tube at $150-160^{\circ} \mathrm{C} .{ }^{[116]}$ Formation of ynaminophosphonates by electrosynthesis has also been reported. ${ }^{[117]}$ The ynaminophosphonates readily undergo all of the reactions characteristic of ynamines: hydration by water with the formation of acetamides, addition of alcohol with the formation of the corresponding vinyl ethers. ${ }^{[115]}$ The use of tert-butylamine in the reaction with 6 also induces the replacement of halogen, but the reaction is accompanied by isomerisation, giving almost quantitative yields of stable ketenimines. ${ }^{[118,119]}$ The presence of two hydrogen atoms at the nitrogen in the amines permits subsequent prototropic isomerisation with the formation of ketenimines. By way of contrast, reactions with primary phosphines lead to halogen-replaced products with the retention of $\mathrm{C} \equiv \mathrm{C}$ bond and $\mathrm{P}-\mathrm{H}$ bonds. ${ }^{[119]}$ The reaction of ketenimines with water in the presence of catalytic amount of $\mathrm{HCl}$ proceeds smoothly and leads to a high yield of the corresponding amide. ${ }^{[120]}$ Reactions of 2-chloroethynylphosphonates $\mathbf{6}$ have also been studied with a number of charged $\left(\mathrm{EtO}^{-}, t-\mathrm{BuO}^{-}, \mathrm{PhO}^{-}\right)^{[121]}$ and neutral ${ }^{[122]}$ nucleophiles containing one or two nucleophilic centers. Treatment of diethyl 2-chloroethynylphosphonate 6 with binucleophilic reagents such orthophenylenediamine, ortho-aminophenol, 2-aminoethanol leads to phosphorylated benzimidazoles, benzoxazoles and 4,5-dihydroxazoles by a mechanism involving initial substitution of the halogen followed by addition of the second nucleophilic center at the same carbon atom. ${ }^{[122]}$

\section{B. Isomerisation of 1-Alkynylphosphonates}

Due to the ready accessibility of 1-alkynylphosphonates 13, their isomerisation to conjugated dienes represents an useful synthetic transformation. In the presence of $\mathrm{Pd}_{2}(\mathrm{dba})_{3} \mathrm{CHCl}_{3}$, the thermal isomerisation of diethyl 1-alkynylphosphonates $\mathbf{1 3}\left(\mathrm{R}^{1}=\mathrm{Me}, \mathrm{Et}, n\right.$ - $\mathrm{Pr}, n$ - $\left.\mathrm{Bu}\right)$ into diethyl $1 E, 3 E$-alkadienylphosphonates occurs at $30{ }^{\circ} \mathrm{C}$ in toluene, whereas at $110{ }^{\circ} \mathrm{C}$ isomeric $2 E, 3 E$-alkadienylphosphonates are formed. The transformation is effected with good yields (79$92 \%)$, but requires lengthy reaction times $(24-69 \mathrm{~h}) .{ }^{[123]}$ The same isomerisation reaction has been effected with $\mathrm{Bu}_{3} \mathrm{P} .{ }^{[124]}$

\section{Reactions of 3-halogenopropynylphosphonates}

3-Halogenopropynylphosphonates have been used as phosphonate-containing acetonyl equivalents. 3-Hydroxypropynylphosphonate intermediates, readily obtained through the reaction of lithium reagents of protected propargyl alcohol upon chlorophosphate (section B. 2) are converted into mesylates, and then to iodide 57 by displacement with sodium iodide, ${ }^{[60]}$ or bromide using $\mathrm{Ph}_{3} \mathrm{P}$ $/ \mathrm{CBr}_{4}$ in $\mathrm{CH}_{2} \mathrm{Cl}_{2}{ }^{[125]}$ Subsequent treatment of the diethyl 3-iodopropynylphosphonate $\mathbf{5 7}$ with ketone enolates (formed using KHMDS / triethylborane in THF) gave the corresponding alkylation products 58 which were hydrolyzed to the expected $\beta$-ketophosphonates 59 (Scheme 24). ${ }^{[6]}$ The reaction has been successfully extended to the preparation of diketophosphonates ${ }^{[92]}$ as well as amino derivatives of phosphonopentynoic acid. ${ }^{[125]}$ 

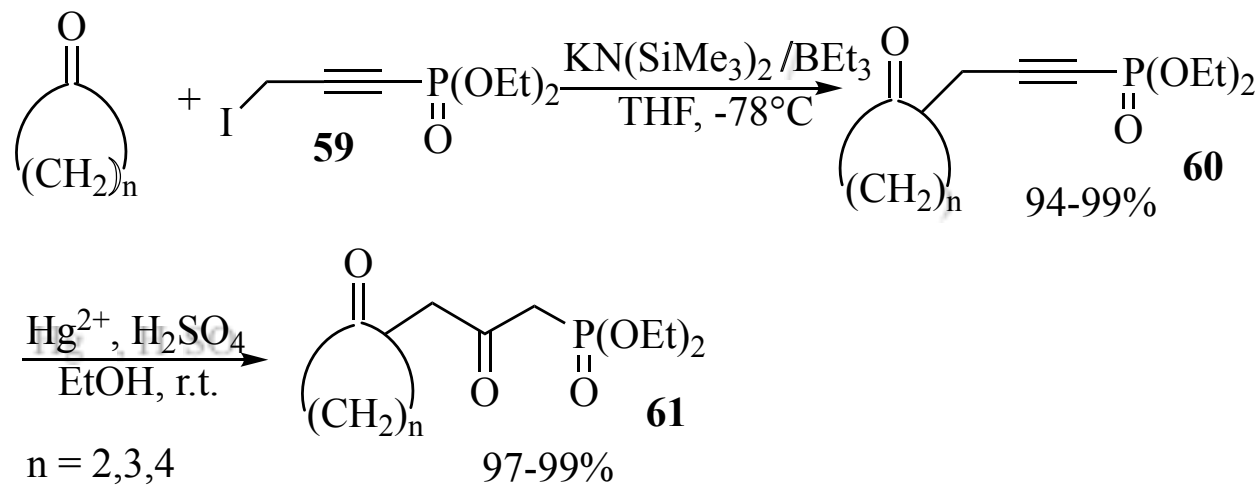

Scheme 24

Metallation of diethyl 1-propynylphosphonate $18(\mathrm{R}=\mathrm{Et})$ has been achieved by treatment with alkaline amides ( $\mathrm{Li}, \mathrm{Na}, \mathrm{K}$ ) and calcium in liquid ammonia, with isopropylmagnesium chloride in $\mathrm{Et}_{2} \mathrm{O}$ or via metal exchange from the potassium derivative of diethyl 1-propynylphosphonate $\mathbf{1 8}$ $(\mathrm{R}=\mathrm{Et})$ with copper (I) and cobalt (II) chloride. The alkylation of the potassium derivative with alkyl halides and the hydroxyalkylation with benzaldehyde occur with low yields at the $\gamma$-position of the parent compound. ${ }^{[126]}$

\section{Reactions at Phosphorus}

Bromo- and iodotrimethylsilane, reagents compatible with alkyne and other functionalities, are suitable for the mild $\mathrm{P}-\mathrm{O}$ dealkylation of symmetrical 1-alkynylphosphonates 3 to give the corresponding phosphonic acids. ${ }^{[127-129]}$ The greater reactivity of iodotrimethylsilane will probably prove advantageous for the low-temperature dealkylation of phosphonates having triple bonds. Transesterification of diethyl 2-propynylphosphonate with iodotrimethylsilane followed by solvolysis with $\mathrm{MeOH}$ led quantitatively to the 1-propynylphosphonic acid. ${ }^{[128]}$

Two procedures for the transformation of diesters of 1-alkynylphosphonates 3 into monoesters have been described. They involve the selective replacement of one ethoxy group by chlorine without addition to the triple bond. Treatment of diethyl 1-propynylphosphonate $18(\mathrm{R}=$ Et) with $\mathrm{POCl}_{3}$ neat $\left(1.2\right.$ eq.) at $60^{\circ} \mathrm{C}$ for $3 \mathrm{~h}$ gives the ethyl 1-propynylphosphonochloridate $\mathbf{6 0}$ in $79 \%$ yield. ${ }^{[130]}$ Similarly, treatment of $18(\mathrm{R}=\mathrm{Et})$ with trichloro(orthophenylenedioxy)phosphorane for $24 \mathrm{~h}$ gives 60 in $74 \%$ yield. ${ }^{[131]}$ The transformation into phosphonic dichlorides 61 is achieved by the reaction of $18(\mathrm{R}=\mathrm{Et})$ with $\mathrm{PCl}_{5}$ on heating at 110 $135^{\circ} \mathrm{C}$ for $1 \mathrm{~h}$ (Figure 4). ${ }^{[132]}$<smiles>CC#CP(=O)(Cl)OCC</smiles><smiles>CC#CP(=O)(Cl)Cl</smiles>

Figure 4

\section{Conclusion}

The methodologies for the preparation of 1-alkynylphosphonates constitute a valuable class of synthetic reactions. Irrespective of the nature of the alkyne, the elimination route seems to be the most flexible and promising. It would be of interest to apply these approaches to develop a general procedure giving access to 1-alkynylphosphonates containing indifferently alkyl or aryl groups. 1Alkynylphosphonates possess remarkable potential and, in addition to the useful transformation involving simple reduction and hydration reactions of the triple bond, cycloaddition reactions 
appear to offer very attractive synthetic procedures. The use of 1-alkynylphosphonates might be developed more largely in [2+2] and [4+2] reactions and employed in [2+2+2] enynes reactions to prepare new phosphorus reagents and new phosphorus-containing heterocycles.

\section{Acknowledgments}

We are grateful to Elf Atochem S.A. for financial support to B. I., to M. Multan from the Ecole Polytechnique (BCX) for assistance in collecting the literature and the Centre National de la Recherche Scientifique (CNRS).

${ }^{[1]}$ H. I. Jacobson, M. J. Griffin, S. Preis, E. V. Jensen, J. Am. Chem. Soc. 1957, 79, 2608-2612.

${ }^{[2]}$ F. Eymery, B. Iorga, P. Savignac, Tetrahedron 1999, 55, 13109-13150.

${ }^{[3]}$ B. I. Ionin, A. A. Petrov, J. Gen. Chem. USSR (Engl. Transl.) 1962, 32, 2355-2356; Zh. Obshch. Khim. 1962, 32, 2387-2388.

${ }^{[4]}$ B. I. Ionin, A. A. Petrov, J. Gen. Chem. USSR (Engl. Transl.) 1965, 35, 1910-1913 ; Zh. Obshch. Khim. 1965, 35, 1917-1921.

${ }^{[5]}$ E. T. Bogoradovskii, V. S. Zavgorodnii, K. S. Mingaleva, V. L. Maksimov, A. A. Petrov, J. Gen. Chem. USSR (Engl. Transl.) 1978, 48, 1601-1603 ; Zh. Obshch. Khim. 1978, 48, 1754-1757.

${ }^{[6]}{ }^{[6 a]}$ B. I. Ionin, V. B. Lebedev, A. A. Petrov, Dokl. Phys. Chem. (Engl. Transl.) 1963, 152, 831833 ; Dokl. Akad. Nauk SSSR 1963, 152, 1354-1356 - ${ }^{[6 b]}$ B. I. Ionin, K. S. Mingaleva, A. A. Petrov, J. Gen. Chem. USSR (Engl. Transl.) 1964, 34, 2651-2653; Zh. Obshch. Khim. 1964, 34, 2630-2632.

${ }^{[7]}[7$ a] B. I. Ionin, A. A. Petrov, J. Gen. Chem. USSR (Engl. Transl.) 1963, 43, 2791-2795; Zh. Obshch. Khim. 1963, 43, 2963-2868. - ${ }^{[7 b]}$ G. Peiffer, A. Guillemonat, J.-C. Traynard, M. Faure, $C$. R. Acad. Sci., Ser. C 1969, 268, 358-360.

${ }^{[8]}$ S. V. Kruglov, V. M. Ignat'ev, B. I. Ionin, A. A. Petrov, J. Gen. Chem. USSR (Engl. Transl.) 1973, 43, 1470-1478; Zh. Obshch. Khim. 1973, 43, 1480-1490.

${ }^{[9]}$ V. A. Garibina, A. V. Dogadina, V. I. Zakharov, B. I. Ionin, A. A. Petrov, J. Gen. Chem. USSR (Engl. Transl.) 1979, 49, 1728-1735 ; Zh. Obshch. Khim. 1979, 49, 1964-1973.

${ }^{[10]}$ A. I. Senderikhin, A. V. Dogadina, B. I. Ionin, A. A. Petrov, J. Gen. Chem. USSR (Engl. Transl.) 1988, 58, 1483-1484; Zh. Obshch. Khim. 1988, 58, 1662-1663.

${ }^{[11]}$ D. Seyferth, J. D. H. Paetsch, J. Org. Chem. 1969, 34, 1483-1484.

${ }^{[12]}$ E. Fluck, W. Kazenwadel, Z. Naturforsch. (B) 1976, 31, 172-174.

${ }^{[13]}$ A. N. Mirskova, N. V. Lutskaya, M. G. Voronkov, J. Gen. Chem. USSR (Engl. Transl.) 1979, 49, 2365-2367; Zh. Obshch. Khim. 1979, 49, 2668-2670.

${ }^{[14]}$ A. N. Mirskova, S. G. Seredkina, I. D. Kalikhman, M. G. Voronkov, Bull. Acad. Sci. USSR, Div. Chem. Sci. (Engl. Transl.) 1985, 34, 2614-2617 ; Izv. Akad. Nauk SSSR, Ser. Khim. 1985, 34, 28182821.

${ }^{[15]}$ D. W. Burt, P. Simpson, J. Chem. Soc. (C) 1969, 2273-2276.

${ }^{[16]}$ H. B. Lazrek, H. Khaider, A. Rochdi, J.-L. Barascut, J.-L. Imbach, Nucleosides Nucleotides 1994, 13, 811-817.

${ }^{[17]}$ A. A. Petrov, B. I. Rogozev, L. M. Krizhanskii, V. S. Zavgorodnii, J. Gen. Chem. USSR (Engl. Transl.) 1968, 38, 1151; Zh. Obshch. Khim. 1968, 38, 1196-1197.

${ }^{[18]}$ V. S. Zavgorodnii, B. I. Ionin, A. A. Petrov, J. Gen. Chem. USSR (Engl. Transl.) 1967, 37, 898901 ; Zh. Obshch. Khim. 1967, 37, 949-953.

${ }^{[19]}$ E. P. Kyba, S. P. Rines, P. W. Owens, S.-S. P. Chou, Tetrahedron Lett. 1981, 22, 1875-1878.

${ }^{[20]}$ A. Fujii, J. I. Dickstein, S. I. Miller, Tetrahedron Lett. 1970, 3435-3438.

${ }^{[21]}$ P. Simpson, D. W. Burt, Tetrahedron Lett. 1970, 4799-4802.

${ }^{[22]}$ D. W. Burt, P. Simpson, J. Chem. Soc. (C) 1971, 2872-2876.

${ }^{[23]}$ A. Fujii, S. I. Miller, J. Am. Chem. Soc. 1971, 93, 3694-3700.

${ }^{[24]}$ S. I. Miller, J. I. Dickstein, Acc. Chem. Res. 1976, 9, 358-363. 
${ }^{[25]}$ M. Gordon, C. E. Griffin, J. Org. Chem. 1966, 31, 333-334.

${ }^{[26]}$ A. J. Rudinskas, T. L. Hullar, J. Org. Chem. 1977, 42, 2771-2777.

${ }^{[27]}$ L. J. Jennings, M. J. Parratt, Bioorg. Med. Chem. 1993, 3, 2611-2614.

${ }^{[28]}$ J. S. Lodaya, G. F. Koser, J. Org. Chem. 1990, 55, 1513-1516.

${ }^{[29]}$ G. Hägele, S. Goudetsidis, E. Wilke, J. Seega, H. Blum, M. Murray, Phosphorus Sulfur Silicon Relat. Elem. 1990, 48, 131-140.

${ }^{\left[{ }^{30]}\right.}$ P. J. Stang, in Modern Acetylene Chemistry, P. J. Stang and F. Diederich Eds., VCH, Weinheim, 1995, pp. 67-98

${ }^{[31]}$ A. Meisters, J. M. Swan, Aust. J. Chem. 1965, 18, 163-167.

${ }^{[32]}$ G. Sturtz, C. Charrier, H. Normant, Bull. Soc. Chim. Fr. 1966, 1707-1713.

${ }^{[33]}$ A. P. Brestkin, L. A. Vikhreva, N. N. Godovikov, V. S. Gorbatyuk, S. N. Moralev, M. I. Kabachnik, Bull. Acad Sci. USSR, Div. Chem. Sci. (Engl. Transl.) 1988, 58, 1900-1905 ; Izv. Akad. Nauk SSSR, Ser. Khim. 1988, 58, 2118-2123.

${ }^{[34]}$ J. M. J. Tronchet, A. P. Bonenfant, Carbohydr. Res. 1981, 93, 205-217.

${ }^{[35]}$ I. N. Azerbaev, N. N. Godavikov, N. B. Abdullaev, B. D. Abiyurov, J. Gen. Chem. USSR (Engl. Transl.) 1978, 48, 1163-1165; Zh. Obshch. Khim. 1978, 48, 1271-1273.

${ }^{[36]}$ E. K. Gafurov, L. K. Sal'keeva, M. F. Shostakovskii, J. Gen. Chem. USSR (Engl. Transl.) 1982, 52, 2408-2410; Zh. Obshch. Khim. 1982, 52, 2730-2733.

${ }^{[37]}$ H. Suzuki, H. Abe, Tetrahedron Lett. 1996, 37, 3717-3720.

${ }^{[38]}$ C. M. Welch, E. J. Gonzales, J. D. Guthrie, J. Org. Chem. 1961, 26, 3270-3273.

${ }^{[39]}$ R. A. Khachatryan, S. A. Ovsepyan, M. G. Indzhikyan, J. Gen. Chem. USSR (Engl. Transl.) 1987, 57, 1524-1525; Zh. Obshch. Khim. 1987, 57, 1709-1711.

${ }^{[40]}$ E. N. Opaleva, A. V. Dogadina, B. I. Ionin, Russ. J. Gen. Chem. (Engl. Transl.) 1995, 65, 13441347 ; Zh. Obshch. Khim. 1995, 65, 1467-1470.

${ }^{[41][41 a]}$ A. N. Pudovik, I. M. Aladzheva, J. Gen. Chem. USSR (Engl. Transl.) 1963, 33, 700-701 ; Zh. Obshch. Khim. 1963, 33, 707-708 - ${ }^{[41 \mathrm{~b}]}$ A. N. Pudovik, I. M. Aladzheva, Dokl. Chem. (Engl. Transl.) 1963, 151, 634-637 ; Dokl. Akad. Nauk SSSR 1963, 151, 1110-1113 - ${ }^{[41 \mathrm{c}]}$ A. N. Pudovik, I. M. Aladzheva, L. M. Yakovenko, J. Gen. Chem. USSR (Engl. Transl.) 1963, 33, 3373-3374; Zh. Obshch. Khim. 1963, 33, 3443-3444.

${ }^{[42]}$ A P. Boisselle, N. A. Meinhardt, J. Org. Chem. 1962, 27, 1828-1833.

${ }^{[43]}$ V. Mark, Tetrahedron Lett. 1962, 281-285.

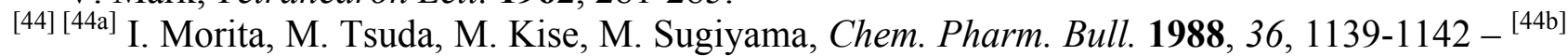

M. Kise, I. Morita, M. Tsuda, JP 62226992, 1987 ; Chem. Abstr. 1989, 111, 39581.

${ }^{[45]}$ B. I. Ionin, A. A. Petrov, J. Gen. Chem. USSR (Engl. Transl.) 1964, 34, 1165-1170; Zh. Obshch. Khim. 1964, 34, 1174-1179.

${ }^{[46]}$ S. H. Pines, S. Karady, GB 1221738, 1969 ; Chem. Abstr. 1970, 72, 132965.

${ }^{[47][47 a]}$ H. Normant, G. Sturtz, C. R. Acad. Sci. 1965, 260, 1984-1987 - ${ }^{[47 b]}$ G. Sturtz, Bull. Soc. Chim. Fr. 1967, 1345-1353.

${ }^{[48]}$ A. N. Pudovik, I. M. Aladzheva, L. N. Yakovenko, J. Gen. Chem. USSR (Engl. Transl.) 1965, 35, 1214-1220; Zh. Obshch. Khim. 1965, 35, 1210-1217.

${ }^{[49]}$ N. M. Ivakina, Yu. A. Kondrat'ev, S. Z. Ivin, J. Gen. Chem. USSR (Engl. Transl.) 1967, 37, 1612-1613; Zh. Obshch. Khim. 1967, 37, 1691.

${ }^{[50]}$ Yu. A. Kondrat'ev, V. V. Tarasov, A. S. Vasil'ev, N. M. Ivakina, S. Z. Ivin, J. Gen. Chem. USSR (Engl. Transl.) 1968, 38, 1745-1747 ; Zh. Obshch. Khim. 1968, 38, 1791-1794.

${ }^{[51][51 \mathrm{a}]} \mathrm{K}$. Iuchi, S. Iwashiro, JP 52131530, 1977 ; Chem. Abstr. 1978, 88, $105561-{ }^{[51 \mathrm{~b}]} \mathrm{K}$. Iuchi, S. Iwashiro, JP 52131532, 1977 ; Chem. Abstr. 1978, 88, 105562.

${ }^{[52]}$ W. Welter, A. Hartmann, M. Regitz, Chem. Ber. 1978, 111, 3068-3085.

${ }^{[53]}$ B. B. Hunt, B. C. Saunders, P. Simpson, Chem. Ind. (London) 1960, 47.

${ }^{[54]}$ B. C. Saunders, P. Simpson, J. Chem. Soc. 1963, 3351-3360.

${ }^{[55]}$ R. M. Acheson, P. J. Ansell, J. R. Murray, J. Chem. Res. (M) 1986, 10, 3001-3019 ; J. Chem. Res. (S) 1986, 378-379.

${ }^{[56]}$ M. S. Chattha, A. M. Aguiar, J. Org. Chem. 1971, 36, 2719-2720. 
${ }^{[57]}$ J. M. J. Tronchet, A. P. Bonenfant, K. D. Pallie, F. Habashi, Helv. Chim. Acta 1979, 62, $1622-$ 1625 .

${ }^{[58]}$ A. J. Rudinskas, T. L. Hullar, J. Med. Chem. 1976, 19, 1367-1371.

${ }^{[59]}$ S. V. Stepanova, S. D. L'vova, V. I. Gunar, Bioorg. Khim. 1978, 4, 682-687 ; Chem. Abstr. 1978, 89, 59939.

${ }^{[60]}$ A. J. Poss, R. K. Belter, J. Org. Chem. 1987, 52, 4810-4812.

${ }^{[61]}$ R. M. Acheson, P. J. Ansell, J. Chem. Soc., Perkin Trans. 1 1987, 1275-1281.

${ }^{[62]}$ A. Knierzinger, A. Grieder, P. Schönholzer, Helv. Chim. Acta 1991, 74, 517-530.

${ }^{[63]}$ S. M. Ruder, B. K. Norwood, Tetrahedron Lett. 1994, 35, 3473-3476.

${ }^{[64]}$ R. W. Saalfrank, A. Welch, M. Haubner, U. Bauer, Liebigs Ann. 1996, 171-181.

${ }^{[65]}$ J. M. Gil, J. W. Sung, C. P. Park, D. Y. Oh, Synth. Commun. 1997, 27, 3171-3174.

${ }^{[66]}$ S. D. L’vova, Yu. P. Kozlov, V. I. Gunar, J. Gen. Chem. USSR (Engl. Transl.) 1977, 47, 11531157 ; Zh. Obshch. Khim. 1977, 47, 1251-1256.

${ }^{[67]}$ C. Blanchard, M. Vaultier, J. Mortier, Tetrahedron Lett. 1997, 38, 8863-8866.

${ }^{[68][68 a]}$ J. M. Cox, T. R. Hawkes, P. Bellini, R. M. Ellis, R. Barrett, J. J. Swanborough, S. E. Russell, P. A. Walker, N. J. Barnes, A. J. Knee, T. Lewis, P. R. Davies, Pestic. Sci. 1997, 50, $297-$ 311. $-{ }^{[68 \mathrm{~b}]}$ J. M. Cox, P. Bellini, R. Barrett, R. M. Ellis, T. R. Hawkes, US 5393732, 1993 ; Chem. Abstr. 1994, 120, 134813.

${ }^{[69]}$ T. A. Yagudeev, R. K. Kushembaev, A. N. Nurgalieva, S. Zhumagaliev, G. M. Dzhakiyaev, N. N. Godovikov, J. Gen. Chem. USSR (Engl. Transl.) 1980, 50, 1804-1807; Zh. Obshch. Khim. 1980, 50, 2236-2238.

[70] J. Cymerman Craig, M. D. Bergenthal, I. Fleming, J. Harley-Mason, Angew. Chem. Intl. Ed. Engl. 1969, 8, 429-437.

${ }^{[71]}$ E. Negishi, A. O. King, W. L. Klima, W. Patterson, A. Silveira Jr., J. Org. Chem. 1980, 45, 2526-2528.

${ }^{[72]}$ J. E. Hong, C.-W. Lee, Y. Kwon, D. Y. Oh, Synth. Commun. 1996, 26, 1563-1567.

${ }^{[73]}$ Y. Shen, M. Qi, J. Chem. Soc., Perkin Trans. 1 1993, 2153-2154.

${ }^{[74]}$ K. N. Anisimov, B. V. Kopylova, Bull. Acad Sci. USSR, Div. Chem. Sci. (Engl. Transl.) 1961, 253-256 ; Izv. Akad. Nauk SSSR, Ser. Khim. 1961, 277-280.

${ }^{[75]}$ K. A. Petrov, M. A. Raksha, L. D. Khai, J. Gen. Chem. USSR (Engl. Transl.) 1976, 46, 19181922 ; Zh. Obshch. Khim. 1976, 46, 1991-1995.

${ }^{[76]}$ H. L. Slates, N. L. Wendler, Chem. Ind. (London) 1978, 430-431.

${ }^{[77] ~[77 a] ~ A . ~ V . ~ D o g a d i n a, ~ Y u . ~ D . ~ N e c h a e v, ~ B . ~ I . ~ I o n i n, ~ A . ~ A . ~ P e t r o v ., ~ J . ~ G e n . ~ C h e m . ~ U S S R ~(E n g l . ~}$ Transl.) 1971, 41, 1670-1675; Zh. Obshch. Khim. 1971, 41, 1662-1668 - ${ }^{[77 b]}$ A. V. Dogadina, K. S. Mingaleva, B. I. Ionin, A. A. Petrov., J. Gen. Chem. USSR (Engl. Transl.) 1972, 42, 2183-2189; Zh. Obshch. Khim. 1972, 42, 2186-2193 - ${ }^{[77 c]}$ G. F. Nazvanova, V. V. Moskva, T. Sh. Sitdikova, F. A. Kashfarova, Izv. Vyssh. Uchebn. Zaved., Khim. Khim. Tekhnol. 1982, 25, 37-40 ; Chem. Abstr. 1982, 96, 217937.

${ }^{[78]}$ M. Murayama, S. Matsumura, Y. Etsure, M. Ozaki, JP 50010571, 1975 ; Chem. Abstr. 1975, 83, 164368.

${ }^{[79]}$ R. G. Hall, S. Trippett, Tetrahedron Lett. 1982, 23, 2603-2604.

${ }^{[80]}$ L. N. Jungheim, S. K. Sigmund, J. Org. Chem. 1987, 52, 4007-4013.

${ }^{\left[{ }^{81]}\right.}$ R. Dizière, P. Savignac, Tetrahedron Lett. 1996, 37, 1783-1786.

${ }^{\left[{ }^{22]}\right.}$ Y. Shen, Y. Lin, Y. Xin, Tetrahedron Lett. 1985, 26, 5137-5138.

${ }^{[83]}$ W. H. Midura, M. Mikolajczyk, Tetrahedron Lett. 1995, 36, 2871-2874.

${ }^{[84]}$ B. G. Christensen, W. J. Leanza, G. Alberts-Schonberg, GB 1239986, 1968 ; Chem. Abstr. 1970, $72,67109$.

${ }^{[85]}$ B. G. Christensen, W. J. Leanza, G. Alberts-Schonberg, US 3929840, 1974 ; Chem. Abstr. 1976, 84, 90302.

${ }^{[86]}$ A. J. Rudinskas, T. L. Hullar, J. Org. Chem. 1976, 41, 2411-2417.

${ }^{[87]}{ }^{[87 a]}$ H.-J. Cristau, M.-B. Gasc, X. Y. Mbianda, J. Organomet. Chem. 1994, 474, C14-C15. - ${ }^{[87 b]}$

H.-J. Cristau, X. Y. Mbianda, Y. Beziat, M.-B. Gasc, J. Organomet. Chem. 1997, 529, 301-311. 
${ }^{[88]}$ G. M. Blackburn, A. R. Forster, M.-J. Guo, G. E. Taylor, J. Chem. Soc., Perkin Trans. 1 1991, 2867-2871.

${ }^{[89]}$ Y. Machida, I. Saito, J. Org. Chem. 1979, 44, 865-866.

${ }^{[90] ~[90 a]}$ C. F. Bigge, G. Johnson, D. F. Ortwine, J. T. Drummond, D. M. Retz, L. J. Brahce, L. L. Coughenour, F. W. Marcoux, A. W. Probert, Jr., J. Med. Chem. 1992, 35, 1371-1384. - ${ }^{[90 b]}$ C. F. Bigge, G. Johnson, US 5179085, 1993 ; Chem. Abstr. 1993, 119, 96171.

${ }^{[91]}$ R. S. Todd, M. Reeve, A. H. Davidson, WO 9322321, 1993 ; Chem. Abstr. 1994, 120, 245504.

${ }^{[92][92 \mathrm{a}]}$ E. J. Corey, S. C. Virgil, J. Am. Chem. Soc. 1990, 112, 6429-6431.- ${ }^{[92 b]}$ S. D. Guile, J. E.

Saxton, M. Thornton-Pett, J. Chem. Soc., Perkin Trans. 1 1992, 1763-1767.

${ }^{[93]}$ G. Peiffer, P. Courbis, Can. J. Chem. 1974, 52, 2894-2900.

${ }^{[94]}$ E. Öhler, E. Zbiral, Monatsch. Chem. 1984, 115, 493-508.

${ }^{[95]}$ A. N. Pudovik, N. G. Khusainova, T. V. Timoshina, J. Gen. Chem. USSR (Engl. Transl.) 1974, 44, 257-260; Zh. Obshch. Khim. 1974, 44, 272-276.

${ }^{[96]}$ K. Matoba, H. Yonemoto, M. Fukui, T. Yamazaki, Chem. Pharm. Bull. 1984, 32, 3918-3925.

${ }^{[97]}$ Y. Shen, J. Zheng, Y. Xin, Y. Lin, M. Qi, J. Chem. Soc., Perkin Trans. 1 1995, 997-999.

${ }^{[98]}$ N. G. Khusainova, E. A. Irtuganova, R. A. Cherkasov, Russ. J. Gen. Chem. USSR (Engl. Transl.) 1995, 65, 1017-1020; Zh. Obshch. Khim. 1995, 65, 1115-1119.

${ }^{[99][99 a]}$ A. N. Pudovik, N. G. Khusainova, E. A. Berdnikov, Z. A. Nasybullina, J. Gen. Chem. USSR (Engl. Transl.) 1974, 44, 213 ; Zh. Obshch. Khim. 1974, 44, 222. - ${ }^{[99 b]}$ A. N. Pudovik, N. G. Khusainova, Z. A. Bredikhina, E. A. Berdnikov, Dokl. Chem. (Engl. Transl.) 1976, 226, 52-53 ; Dokl. Akad. Nauk SSSR 1976, 226, 364-365.

${ }^{[100]}$ N. G. Khusainova, Z. A. Bredikhina, E. A. Berdnikov, A. I. Konovalov, A. N. Pudovik, J. Gen. Chem. USSR (Engl. Transl.) 1977, 47, 1339-1344 ; Zh. Obshch. Khim. 1977, 47, 1456-1461.

${ }^{[101][101 \mathrm{a}]}$ F. Palacios, A. M. Ochoa de Retana, J. Pagalday, Heterocycles 1994, 38, 95-102. - ${ }^{[101 \mathrm{~b}]}$ F. Palacios, A. M. Ochoa de Retana, J. Pagalday, J. M. Sanchez, Org. Prep. Proc. Int. 1995, 27, 603612.

${ }^{[102]}$ F. Louërat, K. Bougrin, A. Loupy, A. M. Ochoa de Retana, J. Pagalday, F. Palacios, Heterocycles 1998, 48, 161-170.

${ }^{[103]}$ N. G. Khusainova, Yu. G. Trishin, E. A. Irtuganova, L. A. Tamm, V. N. Chistokletov, A. N. Pudovik, J. Gen. Chem. USSR (Engl. Transl.) 1991, 61, 545-547; Zh. Obshch. Khim. 1991, 61, 601-603.

${ }^{[104]}$ A. N. Pudovik, N. G. Khusainova, T. I. Frolova, J. Gen. Chem. USSR (Engl. Transl.) 1971, 41, 2446-2449; Zh. Obshch. Khim. 1971, 41, 2420-2424.

${ }^{[105]}$ S. Lelièvre, F. Mercier, F. Mathey, J. Org. Chem. 1996, 61, 3531-3533.

${ }^{[106]}$ C. L. Ma, X. Y. Lu, Y. X. Ma, J. Chem. Soc., Perkin Trans. 1 1995, 2683-2684.

${ }^{[107]}$ X. Huang, C. Zhang, X. Lu, Synthesis 1995, 769-771.

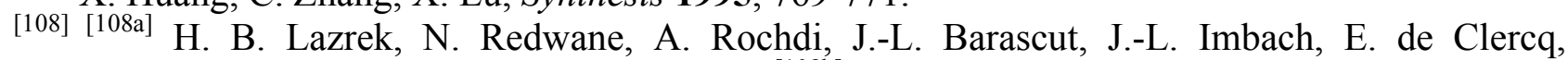
Nucleosides Nucleotides 1995, 14, 353-356. $-{ }^{[108 b]}$ H. B. Lazrek, H. Khaïder, A. Rochdi, J.-L. Barascut, J.-L. Imbach, Tetrahedron Lett. 1996, 37, 4701-4704. - ${ }^{[108 \mathrm{c}]}$ H. B. Lazrek, A. Rochdi, H. Khaïder, J.-L. Barascut, J.-L. Imbach, J. Balzarini, M. Witvrouw, C. Pannecouque, E. de Clercq, Tetrahedron 1998, 54, 3807-3816.

${ }^{[109]}$ M. S. Chattha, A. M. Aguiar, J. Org. Chem. 1973, 38, 2908-2909.

${ }^{[110]}$ M. S. Chattha, Chem. Ind. (London) 1976, 1031-1032.

${ }^{[111]}$ N. G. Khusainova, G. V. Romanov, R. Ya. Nazmutdinov, A. N. Pudovik, J. Gen. Chem. USSR (Engl. Transl.) 1981, 51, 1893-1896 ; Zh. Obshch. Khim. 1981, 51, 2202-2206.

${ }^{[112]}$ A. N. Pudovik, N. G. Khusainova, A. B. Ageeva, J. Gen. Chem. USSR (Engl. Transl.) 1964, 34, 3998-4002; Zh. Obshch. Khim. 1964, 34, 3938-3942.

${ }^{[113]}$ N. G. Khusainova, L. V. Naumova, E. A. Berdnikov, A. N. Pudovik, J. Gen. Chem. USSR (Engl. Transl.) 1984, 54, 1758-1760 ; Zh. Obshch. Khim. 1984, 54, 1971-1974.

${ }^{[114]}$ A. L. Braga, E. F. Alves, C. C. Silveira, L. H. de Andrade, Tetrahedron Lett. 2000, 41, 161163. 
${ }^{[115]}$ V. A. Garibina, A. V. Dogadina, B. I. Ionin, A. A. Petrov, J. Gen. Chem. USSR (Engl. Transl.) 1979, 49, 2104-2105; Zh. Obshch. Khim. 1979, 49, 2385-2386.

${ }^{[116]}$ B. I. Ionin, A. A. Petrov, J. Gen. Chem. USSR (Engl. Transl.) 1965, 35, 2247 ; Zh. Obshch. Khim. 1965, 35, 2255.

${ }^{[117]}$ J. C. Le Menn, J. Sarrazin, A. Tallec, Electrochim. Acta 1991, 36, 819-823.

${ }^{[118]}$ A. A. Leonov, A. V. Dogadina, B. I. Ionin, A. A. Petrov, J. Gen. Chem. USSR (Engl. Transl.) 1983, 53, 205-206; Zh. Obshch. Khim. 1983, 53, 233-234.

${ }^{[119]}$ A. A. Leonov, O. I. Tuzikov, V. Yu. Lomakin, V. Ya. Komarov, A. V. Dogadina, B. I. Ionin, A. A. Petrov, J. Gen. Chem. USSR (Engl. Transl.) 1984, 54, 1269-1270 ; Zh. Obshch. Khim. 1984, 54, 1422-1423.

${ }^{[120]}$ A. A. Leonov, V. Ya. Komarov, A. V. Dogadina, B. I. Ionin, A. A. Petrov, J. Gen. Chem. USSR (Engl. Transl.) 1985, 55, 26-32; Zh. Obshch. Khim. 1985, 55, 32-39.

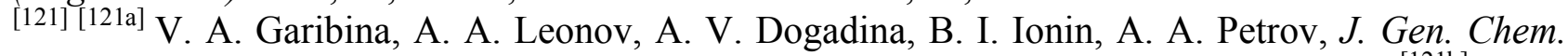
USSR (Engl. Transl.) 1985, 55, 1771-1781; Zh. Obshch. Khim. 1985, 55, 1994-2006. - ${ }^{[121 b]}$ V. N. Drozd, E. N. Komarova, V. A. Garibina, J. Org. Chem. USSR (Engl. Transl.) 1987, 23, 2180 ; Zh. Org. Khim. 1987, 23, 2467-2468.

${ }^{[122]}$ V. A. Garibina, A. A. Leonov, A. V. Dogadina, B. I. Ionin, A. A. Petrov, J. Gen. Chem. USSR (Engl. Transl.) 1987, 57, 1321-1327; Zh. Obshch. Khim. 1987, 57, 1481-1488.

${ }^{[123]}$ C. L. Ma, X. Y. Lu, Y. X. Ma, Main Group Metal Chem. 1995, 18, 391-397.

${ }^{[124]}$ C. L. Ma, X. Y. Lu, Y. X. Ma, Chin. Chem. Lett. 1995, 6, 747-750.

${ }^{[125]}$ C. Harde, K.-H. Neff, E. Nordhoff, K.-P. Gerbing, B. Laber, H.-D. Pohlenz, Bioorg. Med. Chem. Lett. 1994, 4, 273-278.

${ }^{[126]}$ M. Kirilov, G. Petrov, A. Sidjimov, Monatsch. Chem. 1980, 111, 1351-1358.

${ }^{[127]}$ G. M. Blackburn, D. Ingleson, J. Chem. Soc., Chem. Commun. 1978, 870-871.

${ }^{[128]}$ G. M. Blackburn, D. Ingleson, J. Chem. Soc., Perkin Trans. 1 1980, 1150-1153.

${ }^{[129]}$ C. E. McKenna, J. Schmidhauser, J. Chem. Soc., Chem. Commun. 1979, 739.

${ }^{[130]}$ X. Morise, P. Savignac, J. C. Guillemin, J. M. Denis, Synth. Commun. 1991, 21, 793-798.

${ }^{[131]}$ N. G. Khusainova, V. F. Mironov, R. A. Cherkasov, Russ. J. Gen. Chem. USSR (Engl. Transl.) 1995, 65, 1445-1446; Zh. Obshch. Khim. 1995, 65, 1578-1579.

${ }^{[132]}$ L. N. Mashlyakovskii, B. I. Ionin, J. Gen. Chem. USSR (Engl. Transl.) 1965, 35, 1582-1587 ;

Zh. Obshch. Khim. 1965, 35, 1577-1584. 